\title{
TOBACCO LEAVES
}

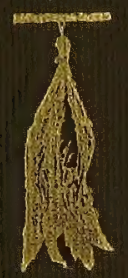

BRENNAN 


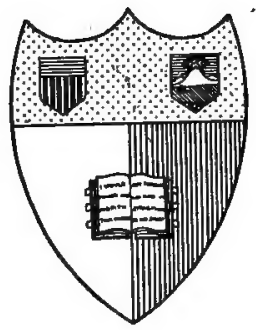

\section{A̛u 想urk \\ State Callege af Agriculture \\ At Garnell Aniuergity \\ Jtḩara. N. 照.}

\section{Thithraxy}




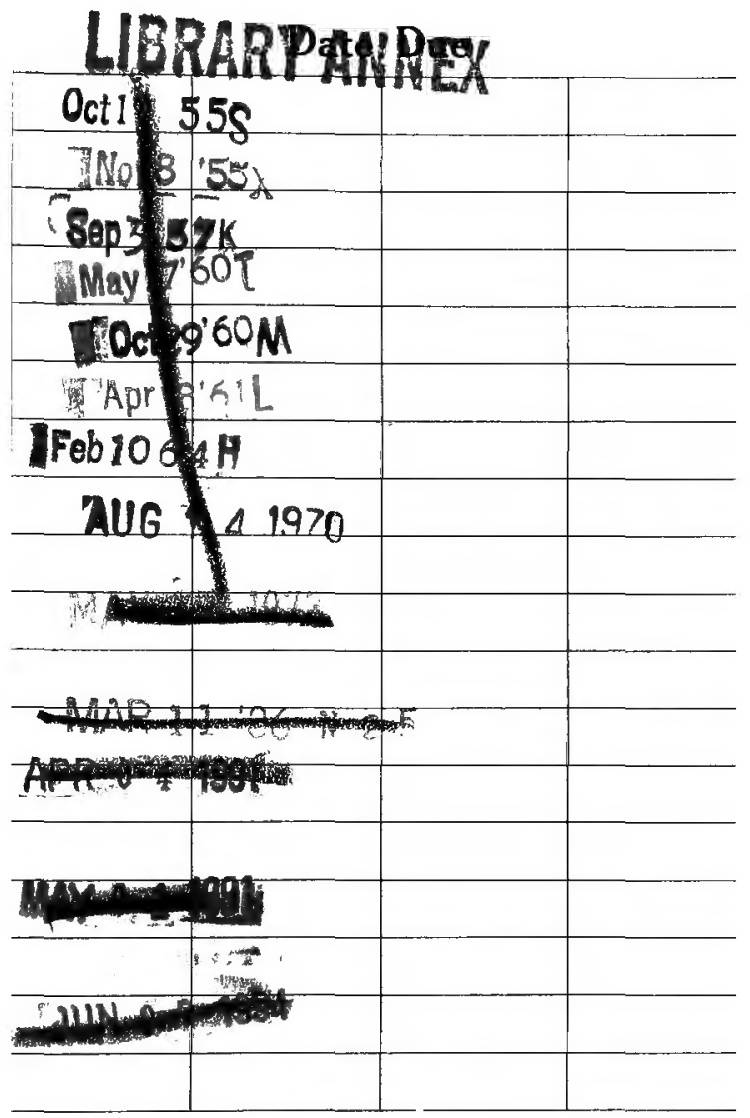

Library Bureau Cat. No. 1137

SB 273.B8 ${ }^{\text {Cornell University Library }}$

Tobacco leaves; being a book of facts for

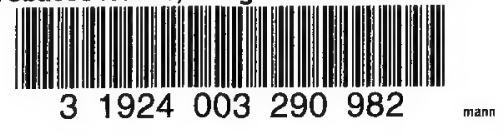




\section{Cornell University Library}

The original of this book is in the Cornell University Library.

There are no known copyright restrictions in the United States on the use of the text. 





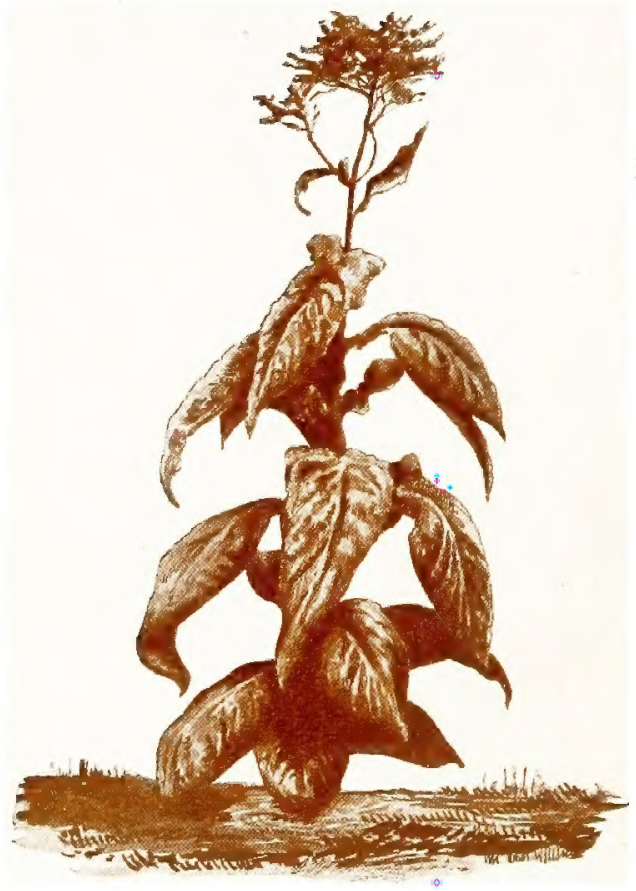

PI.ANT OF KENTUCKY TOBACCO From a Sketch by W. A. Brennan 


\section{TOBACCO LEAVES}

BeING

A Bоoк of Facts

For SMOKERS

BY

W. A. BRENNAN

Department of Medical Sciences

The John Crerar Library

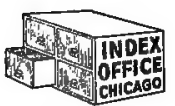

PUBLISFED FOR.

Index Office, Inc.

BY

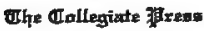

Grorge Banta Publishing Company

Manasha, Wisoongin

1915 
First issue

December, 1915

\author{
@ \\ 513273 \\ B8
}

\title{
Copyright 1915
}

by

W. A. BRENNAN

@16320 


\section{CONTENTS}

PAGE

INTRODUCTION • • . . . . . . . .

Chapter I . . . . • • • • • • . 11

Historical, Botanical.

Chapter II .

The Cultivation of the Tobacco Plant.

Climatic and soil conditions-Treatment of the growing plant-Shade grown tobacco-Harvesting.

Chapter III

Production of Tobacco.

Countries which produce tobacco and amount-Production in the New World other than in the United StatesVarieties.

Chapter IV

Production of Tobacco in the United States.

Total production-Amount produced by the different States-Varieties raised -Description of the different varieties.

Chapter V .

The Chemical Composition of the Tobacco Plant.

Organic and inorganic matters contained in tobacco and the part they play-Analysis of various tobaccos-Nicotine.

Chapter VI

The Curing of Tobacco Leaf.

Objects of curing-Methods. 
Chapter VII

The Marketing and Sale of Tobacco Leaf.

Methods of disposal by the grower-The warehouse system-Direct purchasePrincipal markets in the United States -Prices.

Chapter VIII . . . . . . . . . 75

Rehandling and Fermentation of Tobacco Leaf Prior to Manufacture.

Selection of leaf-Treatment and blending-Objects and methods of manufacturers fermentation - Action of microbes.

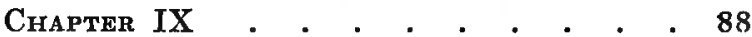

Manufactured Products of Tobacco in the United States.

Statistics of production and consumption Amount of capital invested-Number of plants, etc.

Chapter $\mathbf{X}$

Cigars: Historical and General Facts.

History-Statistical information regarding the cigar business in the United States.

Chapter XI

Cigars and Their Qualities.

Qualities of cigars and cigar leaf-Imported cigars - Havanas - Domestic cigars. 
Chapter XII

Cigar Making.

Hand-made cigars-Machine-made cigars -Classification of cigars--Terms used in the cigar trade.

Chapter XIII

Pipe Smoking and Chening Tobacco.

Qualities required-Description of kinds

Perique tobacco-Statistics.

Chapter XIV . . . . . . . . . 131 Cigarettes.

Statistics-Kinds and where made-Imported cigarettes-Domestic cigarettes -Cigarette papers.

Chapter XV Snuff.

How made-Qualities-Description of kinds.

Chapter XVI . . . . . . . . . 149

Tobacco Smoking Pipes.

History-How made and materials used in making-Meerschaum-Briar rootAmber-Special kinds of pipes-Care of pipes.

Chapter XVII • • • . . • • • . . .

Effects of Tobacco Smoking on the Human System.

Physical and other effects-Opinions of medical men quoted and discussed. 
Chapter XVIII • • •

The Beneficial Effects of Tobacco.

Its disinfecting action - A protection against infectious disease - Psychological effects of smoking.

\section{Chapter XIX
Miscellaneous.}

Revenue, taxation, etc., in connection with tobacco-Free imports - The insect pests which attack tobacco- Tobacco flavoring fluids, etc. - Formulae. 


\section{INTRODUCTION}

This little book is intended for the man who uses tobacco. While there is a very extensive literature concerning tobacco, yet it is surprising how few books there are written expressly for the smoker. Much has been written concerning culture, production and manufacture; the historical and anecdotal aspects have been catered for; pamphlets and books abusing and denouncing the use of tobacco are plentiful; but the smoker will find it difficult to get a book just giving him the facts concerning tobacco and smoking, which he ought to know, and omitting matters, which, although interesting, are not necessary. This little book is an attempt to fulfil that purpose; and it is felt that no apology is needed for its appearance. If the average user of tobacco is questioned concerning the matters treated in the following pages, he will be found ignorant of them. This ought not be so. The custom of tobacco smoking is so general and so intimate a part of the daily life of the great majority of men, that a better acquaintance with the plant, its qualities, uses and effects, should be cultivated and welcomed.

No claim is made for originality. The facts here stated have been gathered from various 
sources and the only credit claimed is for putting them together in a concise and consecutive form. The object aimed at is to give information. Whether the custom of tobacco smoking is desirable, whether in any individual case it would be beneficial or otherwise to smoke-these und similar questions are left to the reader's own judgment from the facts and opinions presented, as well as from his own observations. The man who uses tobacco daily should know what he is doing. If statements are made either verbally or in print concerning the custom he should be able to verify them or show that they are incorrect. It is trusted that the information given in these pages will enable him to form a clear judgment whatever the judgment may be.

It may be felt that many aspects of the use of tobacco and matters connected with it have either not been touched on, or only referred to very briefly. The reader who may desire further information will find it in the bibliographical references given throughout the book. These references have generally been consulted by the author and his indebtedness is acknowledged here. 
To My WIfE 

CHAPTER I

\section{HISTORICAL—BOTANICAL}





\section{HISTORICAL}

The history of tobacco commences with the discovery of the New World by Columbus. The Chinese claim that it was known and used by them much earlier, but there appears to be no evidence to support this claim. Columbus found the natives of Cuba smoking the dried leaves, and his followers are said to have brought the plant to Spain about 1512. Oviedo published a book entitled La Historia general de las Indias in Seville in 1526, in which he mentions pipe smoking. It may be inferred that this custom was well established in Spain then. Sir Walter Raleigh is usually credited with having brought tobacco to England for the first time from Virginia in 1586; and the Virginian Colonists are known to have cultivated the plant at that time; but there is evidence enough to show that Sir Francis Drake was the first to introduce the plant into England. Drake's voyages were made between 1570 and 1580 and he brought the plant with him in one of these. Some give the date of introduction by Drake as 1560. Raleigh was, however, probably the first English distinguished smoker, and he cultivated the plant on his estate at Youghal, Ireland. There is no doubt about the culture of tobacco by the early English Colonists in the U. S., 
but it is doubtful whether the plant was introduced by them from England or whether they continued a culture learned from the $\mathrm{Na}$ tives. From Virginia it spread to the other colonies. In Peru and other parts of South America the growing of tobacco was well established at the time of the Spanish Conquest.

In 1560 Jean Nicot, the French Ambassador at Lisbon, sent some tobacco to Catherine de Medici as a cure for headache. Catherine was pleased with it and is said to have become quite addicted to its use. Tobacco was designated the "Queen's herb" and the "Sovereign herb" from this circumstance and Nicot himself is perpetuated in the word "Nicotine" and its derivatives.

Many persons erroneously give credit to Nicot for the introduction of tobacco into Europe. It is quite clear, however, from Oviedo's book, quoted above; that the plant was known in Spain very much earlier; and it is most probable that the immediate followers of Columbus brought samples of the leaves and pipes back to Spain with them. Moveover, in 1558, Phillip II of Spain sent Francisco Hernandez, a physician, to investigate the resources, etc., of Mexico, and on his return he brought back tobacco as one of the products, and grew it as a drug. From Spain and Eng- 
land, the use of tobacco spread by degrees all over the known world.

\section{REFERENCES}

Penn, W. A. The Soverane Herbe; a history of Tobacco. Chapters I, II. London and New York, 1901.

Bouant, E. Le Tabac; culture et industrie. Paris, 1901.

Shew, Jozx. Tobacco; its history, nature and effects on the body and mind. Wortley, 1876.

Bildrvgs, E. R. Tobacco; its history, varieties, culture, etc. Chapters II, IV. Hartford, Conn., 1895.

Comes, O. Histoire, geographie, statistique du Tabac. Son introduction et son expansion dans tous les pays depuis son origine jusqu' à la fin du XIX siècle. Naples, 1900.

Fatrholt, F. W. Tobacco; its history and associations. London, 1876.

Wolf, Јаков. Der Tabak und die Tabakfabrikate.

Chapter I. Leipzig, 1912.

\section{BOTANICAL}

Tobacco belongs to the family of plants known in botany under the name of Solanacea Other well-known members of this family are the Irish potato, the red pepper, the tomato, the egg-plant, etc. 


\section{American tobacco belongs almost exclusively}

to that group of this family which comprise the genus Nicotiana. Of this genus there are about 50 separate species, one of which, Nicotiana Tabacum, supplies almost all the tobacco of commerce. Plants of this species grow from 2 feet to 9 feet in height; they have numerous wide-spreading leaves sometimes as much as 3 feet in length; these leaves may be oval, oblong, pointed, or lanceolate in shape, and are generally of a pale green color when young; they are arranged alternately in a spiral on the stem; the root is large and fibrous; the stem is erect, round and viscid, branching near the top. The alternate arrangement of the leaves on the stalk, succeeding each other spirally, so that the 9 th overhangs the 1st, the 10th the 2nd, and so on, is very characteristic. The distance on the stalk between the leaves is about 2 inches. Flowers are in large clusters, with corollas of rose color, or white tinged with pink. The leaves and stalks are covered with soft downy hair. The plant is perennial but crops are usually raised from seed.

Of this species (N. Tabacum) there are probably more than 100 varieties grown in the U. S. alone. Some of the best known will be described later. 
To this same species (N. Tabacum) Havana, East Indian and European tobaccos principally belong. The other important species are:

Nicotiana Persica. Grown in Persia. This has a white flower and the leaves almost enwrap the stem. It is used almost exclusively as a pipe-smoking tobacco. Some claim that this is only a variant of $\mathrm{N}$. Tabacum.

Nicotiana Repanda. This is a species of Cuban tobacco entirely different from that grown in the Havana district. It is also called Yara.

Nicotiana Rustica. A kind of wild growing tobacco principally cultivated in Mexico, and which is claimed as the parent of some of the Turkish, Syrian and Latakia tobaccos although many authorities claim that these tobaccos belong to the species $N$. Tabacum. The European tobacco is hardier than the American parent plant. The leaves are smaller.

N. Rustica. Also includes common Hungarian and Turkish tobaccos. There are large and small leaved varieties.

N. Crispa. Grown in Syria and largely in Central Asia. Used as a cigarette tobacco in the Orient.

It has been stated above that there are many varieties of $N$. Tabacum in the U. S. Of these the most important are known to botanists 
by the names, Nicotiana Tabacum Macrophylla and Nicotiana Tabacum Angustifolia.

Maryland tobacco belongs to the Macrophylla variety and there are many other types differing from each other according to shape of the leaf, size of the stalk, etc.

Virginian tobacco is of the Angustifolia variety, and of this also there are many different types.

Most European and other grown tobaccos have been raised from original plants of the Maryland and Virginian varieties.

It should be remembered that there is no essential difference in cigar, pipe smoking or cigarette tobaccos. The differences are physical only. All kinds may be obtained from the same species or even the same variety of the species by suitable culture and crossing.

\section{REFERENCES}

Anastasta, G. E. Le varietá della Nicotiana Tabacum. Scafati, 1906.

Cosces, O. Delle razze dei tabacchi. Naples, 1905. Killebrew, J. B. and Myrick H. Tobacco leaf; its culture and cure, marketing and manufacture. Part I. New York, 1897.

Lock. C. G. W. Tobacco growing, curing, and manufacturing. Chapter I. London and New York, 1886.

Woxf, J. Der Tabac. Chapter II. Leipzig, 1912. Bilings, E. R. Tobacco; its history, varieties, etc. Chapter I. Hartford, Conn., 1875. 


\section{CHAPTER II}

\section{'THE CULTIVATION OF THE TOBACCO PLANT}

Gimatic and Soll Conditions. Treatment of the Growing Plant. Shade Grown Tobacco. Harvesting 



\section{THE CULTIVATION OF THE TOBACCO PLANT}

A few general facts concerning the culture of the tobacco plant and its treatment until it reaches the hands of the manufacturers will be of interest for the smoker.

The general principles underlying the culture of tobacco are the same whether it is intended for the cigar, pipe smoking or cigarette trade; but the treatment of the leaf after it is harvested differs considerably.

Tobacco is a perennial plant. It is, however, usually raised each year from seed. The seedlings are usually ready for planting towards the end of May and are generally planted between the last week in May and the middle of June.

The successful raising of tobacco depends on four principal factors: (1) the climate, (2) the nature of the soil, (3) the seed, and (4) on the method of culture.

The climate must be such as to favor rapid growth and therefore must furnish sufficient heat and moisture during the time the plant is growing. The fineness of the texture and the elasticity of the leaf depend on the climate.

On the soil the plant depends for its food, and for the absorption of those chemical con- 
stituents on which depend the burning qualities, the strength and the color.

The physical qualities of the plant, structure and form, thickness of veins, size, shape and distribution of leaves, are derived from the seed.

Finally, on the method of cultivation (including the curing process) depends in part the final color, flavor and aroma; the type and trade value; that is to say, on successful culture and harvesting and treatment at the right time and in the best way, must depend the grower's hopes of the final value of his crop. The quantity of nicotine, essential oils, etc., on which flavor and strength depend, is regulated to the greatest extent by the time of cutting.

The nature of the soil is a very important matter in the culture of tobacco, for the color of the cured tobacco leaf depends almost entirely on the soil. The light colored leaf is grown on light colored soil and the darker leaf is grown on heavy, dark soil. The best type of soil for the raising of tobacco intended for the cigar trade is a warm, deep, sandy loam which rests on permeable well-drained subsoil. The very light colored yellow tobacco cannot be raised except on light colored, porous soils; and so susceptible is this matter of the coloring of the leaf that it has been noted that the darkening of the soil by a liberal allowance of stable man- 
ure will, on a very light colored soil, change the color of the tobacco leaf from a bright yellow to a mahogany shade. Very light sandy soils or very light loams with clayey subsoils are usually chosen for these light yellow tobaccos. Although by processes subsequent to growth it is possible to darken the color of tobacco leaf, there is no known process that will make a dark leaf light in color.

Moreover, the soil must be very fertile and rich in-the special substances needed by the growing plant. This is all the more necessary because tobacco is a rapidly growing plant, and reaches its maturity within a few months after its planting. The rapidity of growth therefore demands a rich fertile soil well stored with plant food. Good manuring, or liberal treatment with fertilizers, is essential for keeping such soils in prime condition, because the period of growing must not be extended.

Tobacco is usually planted in rows, the rows being from three to four feet apart, the usual arrangement being that the plants are generally about 12 or 18 inches apart in the row. Some planters, however, give the planits more room for many reasons, varying the distance between the plants even as much as 30 inches. Cigar leaf tobacco plants are usually placed about 1.1 inches apart. 
There are various operations necessary during the growth of the plant. The most important of these for our purpose are those known as "priming" or "thinning out" and "cutting." Priming is usually done when the plant is well advanced in growth, but the time varies with different growers and according to the species. It consists in removing the lower or imperfect leaves from the plant, or these which have in any way become injured from insect or other harmful agencies. As a general rule the larger the number of leaves there is on a plant the lower is the quality of the subsequently cured leaf. An average of about 10 leaves to each plant is what is favored by most growers, and the plants are usually thinned to this extent. Seed buds are removed also at the same time and for the same reason. If the plants are "thinned" late and when they are approaching full growth the leaves removed are not destroyed, but are cured separately and sold as inferior quality and are usually called "primings" or "planters lugs."

In the Southern American States the time allowed for the growth and maturing of the plant is somewhat longer than in the eastern and more northerly states where the soil, owing to richer fertilization, favors the rapid growth. Moreover, a stronger quality of tobacco is 
wanted and the extra time allows the plant to effect a greater elaboration in its cells of the oils and gums, etc., which contribute particularly to strength and flavor.

\section{Shade Grown Tobacco}

The matter of rapid growth has, however, its limitations. Too much sunlight is considered a disadvantage. Under such powerful action, nutrition is drawn quickly from the soil and the plants ripen too quickly. Under such circumtstances the leaves tend to become heavy bodied and not very large in size. To defeat this tendency and produce large, thin silky leaves for the cigar trade, the grower sometimes covers his field with a tent of cheese-cloth or similar protection from the glare of the sun. The ripening process is thereby slowed and the leaves are thinner, larger and lighter in shade. This method is employed principally in Cuba, Florida and Connecticut where cigar wrapper leaves are produced, and such tobacco is known as shade-grown.

Tobacco which has been planted out at the end of May or early in June is usually ready for harvesting at the end of August or beginning to middle of September. The actual time of harvesting varies a good deal according to the variety grown and the physical condition con- 
cerned in the growing of the plant. The heavier tobaccos which are intended for the export trade are usually harvested late. The most important operations connected with the culture of the tobacco leaf are the "yellowing" and "curing" processes, and, as these commence with the cutting of the plant, this latter must be done under strictly favorable conditions in order to insure proper results. The cutting must not be done while the sun is very hot, or while there is rain, or before the plant is fully matured. On the other hand, after the plant has reached its maturity, it must not be allowed to continue its growth, which along with other things would be likely to increase its nicotine content which is not desirable. The experienced tobacco grower knows well from the appearance of the plant when it is best fitted for cutting. The leaves become thick and heavy and assume a drooping appearance. They become crisp with a tendency to break easily, and a mottled, spotty look is noticeable on them. The surface becomes gummy and oily; the oily substances increases and exudates as the days pass. When these signs appear the tobacco is cut on the first day when the weather favors. It is usual in most cases to split the stalks down the middle and allow the leaves to wilt, before the stalk is entirely cut through. After sufficient 
wilting the leaves are gathered in piles and exposed to the action of the sunlight; or they are stuck by the stalks on poles or framework and so exposed that the sun and air have free access to all parts. This is the best and most approved practice. "Yellowing" of the leaf is very rapid after the plant is cut; it is the natural effect due to cutting off the food supply of the leaf and the consequent slow death of the vitality of the cells. It must be remembered that the leaves are large, varying in size (according to species) from 12 inches to over 2 feet in length. Such a leaf needs a large quantity of food and the sudden cutting off of the supply effects a rapid change in appearance. The leaves are allowed to hang on the scaffolds 3 to 5 days until they are fully yellowed. They are then ready for the process of "curing," which is the most important operation connected with cultivation. The "curing" and "fermentation" which the leaf undergoes are chemical actions and their success depends on the proper method of "yellowing." The leaves must not be exposed to the sun too long, because the cells would lose their vitality too rapidly and be unfitted for the new part they have to play in the curing process. The chemical changes will be explained in subsequent chapters. It is desired that the reader should 
understand that to ensure a successful final issue the planter has need to watch continuously and to know all the conditions. If the leaf does not "yellow" properly no amount of after care in curing will make up for this deficiency. In tobacco growing as in everything else, to ensure final high quality each step in the process must be executed with skill, care, and judgment.

The yield of tobacco per acre varies from about $300 \mathrm{lbs}$. of leaf in the southern states to $1,000 \mathrm{lbs}$. or more in the eastern. 700 to 800 lbs. per acre is considered a good average crop.

\section{REFERENCES}

Killebrew and Myrick. Tobacco leaf; its culture and cure, marketing and manufacturing. Part I. New York, 1897.

Brllings, E. R. Tobacco; its history, varieties, culture, etc. Chapter XIII. Hartford, Conn., 1875:

LAURENT, L. Le tabac; sa culture et sa préparation production et consummation dans les divers pays. Paris, 1900.

U. S. Dept. of Agriculture. Farmers' Bulletins Nos. 6 and 60 . Tobacco.

U. S. Dept. of Agriculture. Bureau of Plant Industry. Bulletin 96. Tobacco breeding. 


\section{CHAPTER III}

\section{THE WORLD'S PRODUCTION OF TOBACCO}

Total production. Countries which cultivate tobacco. Production in the

NEW WorLd OTHER THAN IN

the United States 



\section{THE WORLD'S PRODUCTION OF TOBACCO}

The world's recorded annual crop of tobacco leaf is over one million tons. The latest government figures available are those for 1912 and 1913, and show 2,696,401,379 and 2,722,190,030 lbs. respectively. Of this amount Asia and America produce each about 350,000 tons, Europe about 250,000 tons and the rest of the world the balance.

The details of the production in the U. S. will be given in the next chapter.

The principal Asiatic countries which produce tobacco are China, Japan, Afghanistan, India, Persia and Asia, Minor. China has an immense production and consumption of tobacco, a large portion of which finds its way into western markets for the cigar and cigarette trade and is sold as "Turkish" tobacco. No figures as to production are available.

British India and Afghanistan produce good tobacco, a lot of which is used in Hindustan and other Eastern countries.

The Persian crop is known to be large, but there are no available records of it. In Persia most of the tobacco raised is of the species known as Nicotiana Persica. This is generally known under its trade name of Tumbach or 
Tumbeki (or more correctly Teymbeki). This is the common Eastern name for tobacco. It is considerably exported to the countries in the neighborhood of Persia and is smoked in the pipe known as the Narghilli. In this pipe the teymbeki burns in contact with a piece of incandescent charcoal. The smoker draws the vapor through a flexible tube which passes to the bottom of a water chamber and passes above it, whence it is inhaled. The narghili is technically a water pipe. The teymbeki is very strong in nicotine, containing up to 5 or 6 per cent.

Japan produces large and medium size leaf of good color but poor in quality. It is generally used for pipe and cigarette trade.

The statistics of production for Asia are extremely unreliable. When we consider the teeming populations of China, India and other Eastern countries and the prevalence of the smoking habit, it is very probable that the figure of production (350,000 tons annually) is much under the mark. There is very little export of tobacco from the United States or Europe to the East. Whatever tobacco is consumed there is mostly of its own production.

European Production of Tobacco

In Europe the principal tobacco producing countries are Germany, France, Austria, Russia, Italy and Turkey. 
Germany has nearly 40,000 acres under tobacco cultivation in Rhenish Bavaria, Baden, Hesse, and Alsace-Lorraine. The annual production is about 50 to 70 million lbs.; and in addition nearly 3 times that much is imported. German home grown leaf is medium to large in size, of fair body, heavy and with coarse veins. It is used for cigar filler and pipe, but is not suited for cigar wrappers." (See the chapter on cigars.)

French tobacco is raised from Virginia seed. It is dark, coarse and heavy and is suitable for plug and snuff making only.

Russia is the largest European producer. Russian tobacco leaf is very large in size and like the French is coarse, dark and heavy and is only fit for plug and snuff making. There is a lighter kind grown from Turkish seed in South Russia which is fit for cigarettes.

Italy has made several attempts to cultivate good tobacco, and several different types are produced. A dark heavy leaf is grown from Virginia seed, and a type from Kentucky seed is also produced. These types are suitable to the dark, heavy fertile soils of Middle and North Italy. In the lighter sandy soil of the south, the varieties grown are raised from Turkish seed and are similar in appearance and quality to the genuine Turkish tobacco. 
Hungary is a heavy grower of tobacco and produces some of the best in Europe. There is a heavy dark type, of a rich brown color, medium sized leaf with small and thin veins, which is used in cigar manufacture. A small bright yellow leaf is also grown, poor in quality and aroma, which is used for pipe smoking and cigarettes.

The most important foreign tobacco as regards U. S. consumers is that known as Turkish. The leaves of the Turkish tobacco are small (about $8^{\prime \prime}$ long), clear yellow in color, and have a special aroma, which renders them peculiarly suitable for the manufacturing of cigarettes. The principal producing centers are Macedonia, Albania, Syria, Palestine and Trebizond, that raised in Macedonia being perhaps the most celebrated. Just like the Cuban leaf, the very best grades of Turkish tobacco are not exported, but are kept for domestic consumption.

Latakia tobacco is produced in the northern part of Syria. This tobacco has a very small nicotine content. It is produced by a special fabrication and is in very great demand as an ingredient of pipe smoking mixtures.

The District of Cavalla in the Province of Roumelia, is one of the most important tobacco centers in the Turkish Empire. There are 
about 75,000 acres under tobacco cultivation and the annual production is about $10,000,000$ lbs. The American Tobacco Co. has a large establishment here through which it purchases its Turkish leaf, amounting to over 6 million lbs. yearly, for the manufacture of Turkish cigarettes, etc.

The total importation of Turkish leaf into the Unițed States during 1913 was:

From Turkey in Europe ... 10,816,048 lbs. From Turkey in Asia ..... 18,955,295 lbs.

Greece and the Balkan States produce tobacco which partakes of the qualities of Hungarian and Turkish, the Grecian leaf being used a good deal as a substitute for genuine Turkish tobacco.

Tobacco produced in the New World other Than In United States

The government of Canada has given a lot of attention to experiments in connection with the growth of tobacco in the Dominion, but only with indifferent success. The leaf is raised principally from Virginian seed, but is large and coarse and is only fit for inferior plug and snuff making.

Cuban Tobacco. The tobacco raised in the Island of Cuba is the most celebrated in the world for cigar making. The leaf is of a rich, 
brown color; narrow and small in size, varying from 8 to 18 inches in length. Its richness of flavor and the peculiar aroma are its chief characteristics. Cuba produces annually about 300,000 to 500,000 bales of tobacco varying in weight from 80 to $150 \mathrm{lbs}$. per bale, nearly onehalf of which is exported to the United States alone.

The importation of Cuban leaf into the United States over a series of years is shown below :

Cuban leaf imports into the U. S. (lbs.)

$\left.\begin{array}{l}1855-1860=7,014,485 \\ 1871-1875=8,985,465 \\ 1886-1890=15,532,075 \\ 1896-1900=10,811,173 \\ 1901-1905=24,048,837\end{array}\right\} \begin{aligned} & \text { Average } \\ & \text { Yearly } \\ & \text { Imports. }\end{aligned}$

Year $1914=26,617,545$

The value in 1900 was $\$ 8,4 \mathbf{r} 8,251$

The value in 1905 was $\$ 13,348,000$

The Province of Pinar del Rio produces about 70 per cent of the entire Cuban crop. In this is the District of Vuelto Abajo which is celebrated the world over for the very finest cigar tobacco. The District of Habana or Havana produces about 13 per cent and Santa Clara about 13 per cent. The Cubans themselves favor the dark "Maduro" fully ripened leaves. At present a good deal of Cuban cigar 
leaf is grown under shade with the result that although when fully mature they are light in color, they are rich in flavor.

The value of the cigar leaf imported by the U. S. from Cuba averages at present about 14 or 15 million dollars annually.

Porto Rican leaf possesses many of the qualities of good Havana leaf, and like the latter is used in cigar manufacture. The annual production is about 120,000 bales. The U. S. imports from 4 to 5 million lbs. annually. Further particulars regarding Cuban and Porto Rican leaf will be given in the chapters concerning cigars.

Mexico produces a tobacco, large as to leaf, dark in color, with heavy body and coarse veins. The tobacco is very strong in flavor. The best grades approach the Cuban tobacco in quality and are imported and used as substitutes for it. The U. S. importation is small. The annual production is about 34 million lbs. The best quality is produced in the neighborhood of Vera Cruz, and only a small portion is exported, principally to Cuba.

Brazilian tobacco leaf is brown in color, medium in size, and medium in body. It posesses fair qualities as a cigar tobacco, for which purpose it is generally used in South America, which is its principal market. 


\section{East Indian and Phimippine Tobacco}

The Dutch East Indies (Sumatra and the adjacent islands) produce yearly about 180 million lbs. of tobacco, all of which is used in the cigar business. Of this the United States takes about from 30,000 to 40,000 bales of Sumatran leaf, about $51 / 2$ million lbs. About 2 lbs. of this leaf wraps 1,000 cigars.

The Philippine Islands produce from 50 to 100 million lbs, of tobacco annually. The crop for 1913 was 101,544,736 lbs. The imports into the United States are principally as manufactured cigars by special arrangements which will be referred to later on in the chapter on cigars. 


\section{CHAPTER IV}

\section{PRODUCTION OF TOBACCO IN THE UNITED STATES}

Total production. Amount produced by the DIfferent States. Varieties raised. Description of the DIFFERENT VARIETIES 



\section{PRODUCTION OF TOBACCO LEAF IN THE UNITED STATES}

The amount of tobacco leaf raised annually in the United States varies from 700 million lbs. to 1,000 million lbs. Thus, according to the Government Statistical Reports, the production in 1909 was $1,055,764,806$ lbs., being an unusually high figure. The production in 1913 was 953,734,000 lbs. and in 1914, $1,034,679,000$ lbs. The average crop may be taken as about 800 million lbs., about half of which is exported as leaf, and the other half manufactured in the U. S. into cigars, smoking and chewing tobaccos, etc., and consumed in the U. S. To produce this immense crop over one million acres of rich, fertile land is under culture, the actual government figures for 1913 being 1,216,000 acres, and for 1914, 1,224,000, and the value of the raw crop is from 80 to 100 million dollars, which works out to an average value of from 10 to 12 cents per $1 b$. The cost of producing the best grades of cigar leaf in the Eastern States is from 8 to 10 cents per lb.; is Wisconsin from 5 to 10 cents. The price paid to the growers is from 5 to 15 cents, except for the highest grades (cigar wrapper leaf) for which special prices, up to 40 or 50 
cents, may be paid. Smoking and chewing leaf of average grade fetches from 6 to 7 cents per $l b$.

From these figures it will be seen that the agricultural industry of tobacco growing is a most important one, and it is constantly increasing both in the quantity produced and in value. About 45 of the states in the Union are engaged in tobacco culture, the principal states and the quantities produced being as follows (for 1914):

Kentucky ........... 364 million lbs.

North Carolina ......... 172 "6 "6

Virginia ............ 114 " "

Tennessee ...........6 63 ". "

Ohio ............. 78 " "6

Wisconsin $\ldots \ldots \ldots \ldots \ldots \ldots 54$ of

Pennsylvania ......... 48 " "

Connecticut ........... 35 " "

South Carolina ......... 36 " "

Maryland ............ 17 " "

Indiana ............ 12 "

Massachusetts ......... 11 " "

Other states .......... 30 "6

Total ........... " "

Virginia was, until recently, the premier tobacco state. Tobacco was first raised in Virginia about 1619 when the quantity pro- 
duced was about 20,000 lbs. By 1753 the records show that over $\mathbf{5 0}$ million lbs. were raised annually, all of which was exported. At this time and until about the period of the Civil War, Europe was dependant more than now on America for her tobacco supply, as at present a considerable part of her needs is supplied by her own production. Tobacco was not grown in Kentucky till about 1785 and a little later in Tennessee and Ohio. The cigar leaf industry of the New England States did not come into activity till about 1830. Cigar leaf was raised in Florida about the same time but was discontinued and was not resumed till fifty years later.

Virginia, Maryland and Tennessee have shown a declining annual production since the Civil War. Thus Virginia in 1860 produced nearly 30 per cent of the total U. S. crop, whereas at present it produces about 12 per cent only. The causes which have contributed to the decline in tobacco culture in the Southern States are the loss of slave labor as well as the loss of capital during the war; more particularly it is due to the impoverishing of the soil without adequate fertilization. Thus with superior fertilization and intensive methods, Massachusetts and Connecticut give 1,750 lbs. to the acre, as against 870 and $580 \mathrm{lbs}$. for 
Kentucky and Tennessee. In Massachusetts and Connecticut the cost for fertilizer per farm is $\$ 227$ as against $\$ 17$ and $\$ 4$ respectively in Tennessee and Kentucky. Moreover, the Northern farms are smaller than the Southern.

\section{Varieties of Tobacco raised}

The varieties of tobacco raised are mainly of the native American species; but in some states (in Florida particularly) plants are raised from imported Cuban and Sumatran seed, in an endeavor to produce cigar leaf equal in quality to the leaf now imported from these places which commands a high price in the trade. The raising of cigar leaf tobacco from foreign seed began in Florida about 1902; and, although on the whole, the cultivation has been very successful, yet it cannot be said that the hoped for results have been fully realized. It was claimed for the Florida grown Sumatran leaf that in many ways it surpassed the native Sumatran leaf. Certainly the experimental samples of this Florida leaf exhibited by the U. S. at the Paris Exposition of 1900 were judged to be superior both in appearance and style and other matters. However, this superiority does not appear to have been upheld, for in the trade the native grown Sumatran leaf still holds its rank. 
Similarly in the case of Florida grown Cuban leaf which at the same Exposition was voted as equal to the native. The native leaf, however, whether due to the soil or not, has a finer flavor and aroma, and the best grades of native grown Cuban tobacco still hold the palm as the premier cigar tobacco of the world.

The leaf raised in Connecticut, Pennsylvania, Ohio, Wisconsin, Florida, Massachusetts, and New York State, is generally used for the cigar trade (see the chapters on cigars). Ohio and Florida (Cuban seed) leaf mostly used as cigar fillers; Connecticut and Florida (Sumatran seed), Pennsylvania and New York leaf mostly as wrapper leaf, the inferior leaves being used as fillers. Wisconsin leaf is used principally as cigar binder leaf. The total amount of cigar tobacco raised is roughly about one-fifth of the entire tobacco crop.

The southern states produce the bulk of the export dark, heavy leaf. West Kentucky and Tennessee particularly, as well as Virginia, the Carolinas and Maryland, export considerable quantities. This tobacco is fire-cured. For the domestic trade, however, (pipe-smoking, chewing and cigarettes) the tobacco grown in these states is flue-cured, the principal product being of a bright yellow color, characteristic of this region. 
This "yellow tobacco belt" extends from the coast across to the North Carolina Mountains, through Tennessee and South Carolina, Southern Virginia, Southern Ohio, a few parts of Kentucky, some of Eastern Missouri and Arkansas. The best soils are those which are of a light sandy or sandy clay nature and they need not be deep or rich. In this region the very finest pipe-smoking tobaccos are raised. Whilst the U. S. has not been able to produce a cigar wrapper tobacco equal in quality to the Cuban or Sumatran, in pipe-smoking and cigarette tobaccos she stands without a rival.

There are about 100 different varieties of tobacco grown in the U. S., many of these being approximately the same and are synonymous. Subvarieties are easily obtained by crossing. Cross-fertilization easily takes place where different strains are produced in the same locality. On this account when it is desired to keep a variety pure, care must be exerted to see that seed is collected from pure strains. On the other hand, the ease of producing new varieties gives opportunity to the various State Agricultural Experimental Stations to try out new strains for desirable qualities. The enumeration of the differences between the various varieties would be tiresome for the reader, yet it will be well for the user of tobacco to know some of these 
varieties, their characteristics and other particulars concerning them. These are given here:

Leading Varieties of American Tobaccos

BURcey. The variety known as White Burley has a long broad leaf, whitish in appearance when growing. The points of the leaf hang down towards the ground when growing, often even touching the ground. The leaf is thin in texture, has a mild flavor, low nicotine content and good absorbing qualities. It is one of the most popular tobaccos in the U. S. and is used for pipe-smoking and chewing tobaccos and cigarettes. It cures to a bright yellow brown color.

There is a variety known as Red Burley which has a thin leaf narrowing from center to top. The leaves are of a characteristic cinnamon color and are more elastic than those of White Burley. Burley tobacco is raised principally in Ohio, Kentucky, Virginia, Maryland, Missouri and Indiana.

Connecticut Large, strong leaves, thin and Seedleaf. elastic, silky in texture, small fibers, sweetish taste and light in color. Used in the cigar trade as fillers and wrappers and grown in New England, 
Pennsylvania, Ohio, and to a smaller extent in Wisconsin, Minnesota, Indiana, Illinois and Florida.

Connecticut A modification of the above, Broadlear. the leaves being broader in proportion to their length. They are up to 35 inches long and 22 inches wide. Largely used in the cigar trade as filler and wrappers. Both the Connecticut Seedleaf and Broadleaf are superior to the imported Sumatran leaf in flavor and aroma, but are inferior in elasticity and covering qualities.

Grown principally in Connecticut and New York States.

Orisoco. There are 3 varieties of this name:

(1) Short Orinoco. Broad leaf, upright growth and open habit, light colored, much ruffled. Grown in Virginia and Missouri. (2) Big Orinoco. Short, broad leaf. Grown in Virginia, Missouri, North Carolina, Tennessee and West Virginia. (3) Yellow Orinoco. Long, narrow, tapering leaf with fine texture. The sweetest variety grown. Grown in Virginia, Maryland, North Carolina, Tennessee, West Virginia and Missouri. 
Orinoco tobacco leaf is used largely for plug and smoking tobaccos and for the export trade.

Virginian. Sun and air-cured tobacco. Leaf is medium in size. Very bright browy color. Is 'rich in gums and oils which makes it sweet and fragrant and gives it a pleasant taste. Hence it is a favorite chewing tobacco.

Pryor. There are several varieties under this name: (1) Medley or White Pryor has a very broad leaf with silky texture and tough fiber. (2) Blue Pryor. Large, long fine leaf and good color. (3) Silky Pryor. A long sharp-pointed leaf; grows thin on the stalk; very tough and pliant. (4) Yellow Pryor. Heavy, wide leaf, fine bright color, tough and weighs well.

Pryor is used principally for the export trade and to some extent also in the home trade both for cigar and plug and smoking tobaccos. It is grown generally throughout Virginia, North Carolina, Kentucky, Tennessee, Missouri and Indiana, the White variety being extensively grown in Virginia. 
Lrtwe A very favorite pipe-smoking toDuтch. bacco. It has a small nicotine content (less than 1\%). The leaf is small; narrow, thick and short; dark brown in color, glossy surface and sweet in taste. It is grown extensively in the Miami Valley of Ohio.

Sumatra Grown principally in Florida from SEEd. imported Sumatran seed. The leaf is light in weight and color, not long compared with other seedleaf varieties. Very narrow and with fine ribs. Used in cigar trade and grown extensively also in the New England states.

Cuban This has the usual qualities of Cuban SEed. tobacco but with inferior fragrance and aroma to the native grown. Principally raised in Pennsylvania, New York, Wisconsin, Connecticut and Florida for the cigar trade.

Perique. A special variety of tobacco grown only in a small area of Louisiana. The leaf is medium in size, has a fine fiber with small stems. Tough, gummy and glossy. It is grown in a deep, rich soil and grows very rapidly. Its special characteristics are acquired in the curing, which is a special process peculiar 
to itself, and which will be described in the chapter on Manufactured Tobaccos.

REFERENCES

Yearbooks of the United States Department of Agriculture. 1914 and previous.

Hoagland, I. G. The Tobacco Industry. In Quarterly of the National Fire Protection Association. 1907. Vol. I, Nos. 2 and 4.

J ACOBSTEIN, M. The Tobacco Industry in the United States. New York, 1907.

Billings, E. R. Tobacco; its history, varieties, culture, manufacture and commerce. Hartford Conn., 1875. 



\section{CHAPTER V}

\section{THE CHEMICAL COMPOSITION OF THE TOBACCO PLANT}

Organic aNd INORganic MatTers CONTAINED IN Tobacco and THE PARTS THEY PLAY. Analysis of various Tobaccos.

Nicotine. 



\section{THE CHEMICAL COMPOSITION OF THE TOBACCO PLANT}

The tobacco plant when subjected to chemical analysis is found to contain all or most of the following substances:

Mineral Bases. Potash, Lime, Magnesia, Oxides of Iron and Manganese, Ammonia, Silica.

Mineral Acids. Nitric, Hydrochloric, Sulphuric and Phosphoric.

Organic Base. Nicotine.

Organic Acids. Malic, Citric, Acetic, Oxalic,

Pectic and Ulmic.

Other Organic Substances. Nicotianin, Green and Yellow Resin, Wax and Fat, Nitrogenous Substances and Cellulose.

The substances which differentiate tobacco from other plants and form its chief characteristics are Nicotianin, Nicotine and Malic Acid.

The percentage in which the important substances exist in tobacco is given below:

Nicotine ...........From 1 to $9 \%$ Malic and Citric Acids .....From 10 to $14 \%$ Oxalic Acid ............From 1 to $2 \%$ Resins, Oils and Fats .......From 4 to $6 \%$ Pectic Acid ...................... $5 \%$ Cellulose .............From 7 to $8 \%$ Albumenoids ............ About 25\% Ash ................ From 12 to $30 \%$ 
When tobacco is burned, chemical changes occur; the organic and other compounds are decomposed. The volatile matters pass off in the smoke if the combustion is complete, and the mineral ash remains. In ordinary pipe or other tobacco smoking, however, the combustion is not complete and many decomposition products remain with the mineral ash.

In tobacco smoke the following can usually be found: Furfurol, Marsh Gas, Hydrogen Sulphide, Hydrogen Cyanide, Organic Acids, Phenols, Empyreumatic Oils, Pyridine, Picoline Series and possibly some Nicotine.

The ash left after complete combustion is important, as much of the smoking qualities of the tobacco depends on its constituents. An average sample gives the following analysis (in 100 parts) :

Average mineral contents of tobacco ash Potash .................. About 27\% Soda ................... 3 bout $\mathbf{3} \%$ Lime ............................ $40 \%$ Magnesia ........................ $9 \%$ Sodium Chloride ......................... $9 \%$ Sulphuric Acid .................. $\mathbf{3 \%}$ Silica .......................... $5 \%$ Lime Phosphate ............ About $4 \%$ 
Remaris on Some of the Substances Found IN Tobacco

\section{Nicotine}

Of all the substances found in tobacco, nicotine is the most important.

Nicotine in the pure state is a colorless liquid having a specific gravity of $1.02 \%$. It is an organic base having the chemical formula $\mathrm{C}_{10} \mathrm{H}_{14} \mathrm{~N}_{2}$. It is extremely acid and burning to the taste, and is a virulent poison. It easily volatilizes; is inflammable, and is soluble in water, alcohol, ether and some fixed oils. Nicotine has the characteristic peculiar odor of tobacco.

The amount of nicotine in tobacco is said to depend on the nature of the soil in which it is grown; rich, heavy soils and strong nitrogenous manuring favor the production of a large nicotine content; and light, sandy soils the opposite.

Moreover the nicotine content depends on the age and development of the plant.

An investigation by Chuard and Mellet showed nicotine contents of leaves:

In young plants $\gamma$ weeks old contained $.0324 \%$ In plants 10 weeks old contained .... .044r\% In plants 13 weeks old contained .... .4989\% In plants 19 weeks old contained . . . . .9202\% The longer the plant is permitted to grow the larger will be its nicotine content. 
Schlössing has made a similar investigation and found that in the same plant the nicotine content varies from $0.79 \%$ when young to 4.32\% when fully matured. Most nicotine is found in the ribs and veins.

H. B. Cox (American Druggist V. 24, 1894, p. 95) investigated the nicotine contents of various manufactured tobaccos. These were not "proprietary tobaccos" but samples obtained from different sources at random. His results are given here:

\section{Nicotine Contents of Difperent Tonaccos}

\section{Nicotine}

Syrian Tobacco leaf (a) ........ .612\% American Chewing Leaf ......... .935\% Syrian Tobacco Leaf (b) . . . . . . . 1.093\% Chinese Tobacco Leaf ............ 1.902\% Turkish Coarse Cut .......... 2.500\% Golden Virginia (whole strips) .... 2.501\% Gold Flake Virginia .......... 2.501\% Navy Cut (light) .......... 2.530\% Light Kentuckian ........... 2.733\% Navy Cut (dark) . . . . . . . . . 3.64\% Best "Bird's Eye" . . . . . . . . . 3.931\% Cut Cavendish (a) . . . . . . . . 4.212\% Best Shag (a) . . . . . . . . . . 4.907\% Cut Cavandish (b) .......... 4.970\% Best Shag (b) ............ 5.00\% 
Algerian Tobacco (a) ........ 8.813\% French Grown Tobacco ..........8.711\% Algerian Tobacco (b) ........ $8.90 \%$

The average of a number of samples of Syrian tobacco showed 1 to $\mathbf{2 \%}$ nicotine. Manila and Havana 1 to 3\%, Virginia and Kentucky from 2 to $1 \%$, and French tobaccos about $9 \%$.

Most of the nicotine in tobacco becomes volatilized and decomposed during combustion; a small part, however, may form a solution with the water which is also one of the combustion products. One of the decomposition products of nicotine is

\section{Pyridine}

Pyridine is usually found in tobacco smoke. When condensed it is a colorless non-oily liquid and is considerably less toxic than nicotine.

Reference will be made later on to the effects of nicotine and pyridine on the human system.

\section{Potash}

Potash is important as on its amount depends the burning qualities of the tobacco. It is sometimes present in the ash to the extent of $30 \%$, being converted into potassium carbonate by burning. Not only for free burning is the potash valuable, but also for the better volatilization of the nicotine and other substances. 
The more perfect the combustion, the fewer deleterious compounds are formed.

Chlorides, if present, retard the burning of the tobacco, and hence a tobacco which contains a high percentage of chloride, even if it is rich in potash salts, is a poor burning tobacco and therefore faulty. While it is important that the burning should be free and the volatilization as perfect as possible, yet the smoker does not want his tobacco to burn too rapidly. To meet this some manufacturers prepare "sislow burning" tobaccos generally by the addition of some chemical which checks the potash.

The aroma and flavor of the tobacco depend to a great extent on the waxes, resins and oils, as well as on certain of the organic acids.

\section{REFERENCES}

\section{U. S. Dispensatory. 1907 (19th Edition).}

Kissuing. The Chemistry of Tobacco. Scientific American (Supp.) 1905, Vol. 60, No. 1560.

Chuard \& Mencett. Variation de Nicotine dans les differents organes de la plante de Tabac. Comp. Rend. Acad. d. Sc. (Paris) 1912. Vol. 155, p. 293.

Pezzolato, A. Conferenza Sulla Chimica applicato alla technologia del Tabacco. (Rome. 1903.) WoLf, JАсов. Der Tabak und die Tabak fabrikate. Chapter III. Leipzig, 1912.

Schlossing. Sur la production de la nicotine par la culture du Tabac. Compt. Rend. Acad. d. Sc. (Paris), 1910. Vol. 151, p. 23. 


\section{CHAPTER VI}

\section{THE CURING OF TOBACCO LEAF \\ Orjects of curing. Methods.}





\section{THE CURING OF TOBACCO LEAF}

The "curing" of tobacco leaf is the process of drying out which has for its object the following specific actions:

(1) The expelling of the sap and superfluous moisture.

(2) The completion of the "yellowing" process and the fixing of the desired color.

(3) The preservation of the juices, etc., which give the characteristic flavor and aroma.

(4) To give the necessary toughness and suppleness to the leaf.

The first part of the curing is done by the grower in curing sheds on the farm immediately after the cutting of the crop; the final part, or the fermentation part is usually done by the leaf dealer or manufacturer in special buildings called leaf-houses.

There are three methods of curing in use by the growers, i. e., sun curing, air curing, and artificial heat curing. In the case of the tobacco known as Perique the curing process is more or less peculiar to itself. "Sun" and "air" curing are much slower processes than the curing by artificial heat. 
All cigar leaf tobacco is sun-cured, and as a general rule pipe smoking and chewing tobacco are cured by artificial heat.

For the purpose of drying and curing by artificial heat, the leaf is hung up in specially constructed curing houses or sheds. It is found that after the exposure to the sun for the first process of "yellowing" tobacco leaf still contains $1 \mathrm{lb}$. of water approximately in each plant. The first part of the process of curing consists in drawing off this superfluous moisture. Dry heat is applied at a temperature of $90^{\circ} \mathrm{F}$. to $120^{\circ} \mathrm{F}$. for about 16 to 30 hours to effect this. A further exposure of about 48 hours at a temperature of $125^{\circ}$ or so is necessary to complete the curing, and fix the color.

The stems and stalks being thicker take a longer time and generally require 9 to 10 hours further exposure and a temperature which may range as high as $175^{\circ} \mathrm{F}$. before they are fully cured, the temperature being graded hourly until the maximum necessary is reached.

The process of curing varies considerably in different states. Some growers prefer to put the tobacco into the sheds immediately after cutting, and allow very little exposure in the fields. The temperature is usually kept steady at about $90^{\circ} \mathrm{F}$. Again the process is different according to the quality of tobacco 
required. For the heavy type of leaf which is intended for the export trade, the curing in the sheds is done by an open fire, the fuel being usually hardwood logs. The smoky, creosotic flavor is absorbed by the leaf, and, although this flavor is not relished by the smokers of the U. S., it is much liked in Europe. The curing in such cases may last for 4 or even 5 five days. The tobacco is suspended on poles by the stalks and the fires are built on the floor immediately under them so that the carbonaceous products are easily absorbed by the open pores of the leaf.

The chewing and pipe smoking tobacco, as well as cigarette tobaccos including all the bright yellow tobaccos used in the U. S. are usually cured by Flue curing. In this case the heat comes from pipes which run around the curing houses and are fed from a furnace in an adjoining chamber or in a cellar. The temperature can be easily regulated. "Flue" curing is generally completed in about 4 days. "Flue" curing does not clog up the pores of the leaf which therefore remain more absorbent than in the open fire cured tobacco. This is an important matter for the manufacturers because the flue cured leaf will absorb twice as much of the flavoring sauces (which are added to certain 
kinds of tobacco) than tabacco leaf cured by open fires.

Air exposure of 6 to 8 weeks (sometimes extended to 3 or 4 months) is necessary when tobacco is cured by exposure to the sun and air. It is claimed, however, that this method of curing preserves far better the natural flavor of the leaf; and, where flavor and aroma are highly important, this method is always preferred. Hence all cigar leaf tobaccos are cured by exposure to natural sunlight and not by artificial heat.

"Air" curing as distinct from sun curing is generally done in open sheds which are thoroughly ventilated and kept as far as possible at a temperature of about $75^{\circ} \mathrm{F}$. The leaf is usually allowed to cure while attached to the stalk, but Florida curers generally prefer to strip the leaf and treat it separately. The finer classes of pipe smoking tobaccos are air cured.

After the curing is completed the color of the leaf is usually fixed. Generally speaking, the riper the leaf the lighter will be its color when cured. Thus the bottom leaves of the plant will be lighter in color than the upper leaves because they are more mature.

(For references see end of Chapter VIII) 


\section{CHAPTER VII}

\section{THE MARKETING AND SALE OF TOBACCO LEAF}

Methods of disposal by the grower. The Warehouse system. Direct purchase. Principal markets in the United States. Prices. 



\section{THE MARKETING AND SALE OF TOBACCO LEAF}

When the tobacco leaf is fully cured it is at once prepared for the market. The first step is the planters' classification of the leaf. In the case of pipe smoking and chewing tobacco the planter collects all the imperfect, injured leaves, or those inferior from any cause, and ties them in bundles. These are the planters lugs. All other grades are leaf. Slightly injured leaves are classed as loz-leaf or seconds. The others are classed medium, good, fine and selected leaf, according to grade, color, quality, etc.

In the case of cigar leaf tobacco a similar classification is made, more care being taken owing to the very great difference in price between the better and poorer qualities. This difference may be as much as $20 \mathrm{c}$ in the $1 \mathrm{~b}$., the finer and more suitable leaf being eagerly sought for.

Pipe smoking and chewing tobacco leaf is usually packed in hogsheads or cases each weighing from 1,000 to $1,400 \mathrm{lbs}$. The operation of packing the leaf is called "prizing." Cigar leaf is usually put up in "hands." A "hand" consists of from 25 to 75 leaves tied together. Four hands tied together make a 
"carrot" and 80 carrots go to the bale, but the size of the bale varies considerably. The tobacco is then ready for the buyer.

There are two systems of disposing of the planters' product: (1) direct purchase by the manufacturer or by a middleman from the grower; and (2) what is known as the warehouse system. In the southern states the warehouse system prevails. Every important tobacco section in the south has its public warehouse which is under the control and supervision of state law. Many of these warehouses are long established, that at Richmond, Va., dating as far back as 1730, and those at Louisville and Clarksville about 1839.

On appointed days the planter brings his leaf to the warehouse. Here it is entered as "loose leaf" or "inspected leaf." In the case of loose leaf, the tobacco is open to the inspection of prospective buyers, who examine it and afterwards bid on it. In the case of "inspected leaf" the warehouse officials first examine the consignments, grade them and mark them according to their judgment, taking samples. The samples are open to buyers' inspection and form the basis of sale. Tobacco auctions are regularly held when the buyers assemble and bid on the "loose leaf" and "inspected" lots. 
Prices of the various grades are fixed and sales take place at the day's price.

The principal tobacco markets are:

For Kentucky and Tennessee-At Louisville, Clarksville and Cincinnati.

For Maryland and Ohio--At Baltimore.

For North Carolina-At Durham and Winston.

For Virginia-At Richmond.

The warehouse system has the great advantage that the proceedings are open and the prices are recorded and published. Hence growers can know how the market fluctuates and judge the best time for sale. This is not the case when the sale is private between the buyer and seller as is customary in the eastern and northern states. Here the price actually received by the grower is often different from that given out as paid.

The price of tobacco leaf has had many vicissitudes during the past 25 years, the price often having reached so low a point as to discourage producers. Thus at Winston, N. C., the price has gradually fallen from $12.3 \mathrm{c}$ per lb. in 1889 to $6.3 \mathrm{c}$ in 1896 . In the same period Burley leaf at Louisville and Cincinnati fell from $10 \mathrm{c}$ to $71 / 2$ c. Prices similarly dropped in other centers. The price of cigar leaf has latterly increased. In 1900 prices ran from 
6 to 15 cents; in 1905 from 8 to 17 cents. Many conditions at home and abroad affect the price, such as bad harvests or inferior grades of produce.

The tobacco trust has been very unjustly blamed by many for the falling price of tobacco. As a matter of fact and record, however, the concentration of buying power by eliminating the middleman and the small dealers has not only placed the grower in a better position by giving him a better price, as recent records show, but it has benefited the consumer also who can obtain the superior grades at a lower price. It is the middleman's profit that has been cut. Moreover, the concentrated buying power of the large interests here has been an effective force in keeping up tobacco leaf prices against the foreign buyers.- It must be remembered that about half of our crop is exported. The buyers of this portion, who are principally the agents of foreign governments (in the cases where tobacco is a government monopoly as in France, Italy, etc.) assemble at the auctions and bid in the usual way. As this competition is very limited there is always an opportunity for such buyers to agree among themselves as to the limit of prices. This has been one of the important factors which has kept the prices of tobacco leaf down. The con- 
centration of American buying power has, however, been a formidable check on it, the prices received by the growers being now fair and reasonable, and such as are the result of a healthy market, where the factors of supply and demand have their full share of effect.

The government statistics show that for 1914 the prices of leaf varied from $5.5 \mathrm{c}$ to $20 \mathrm{c}$ for common to good varieties.

- (For references see end of Chapter VIII) 



\section{CHAPTER VIII}

\section{REHANDLING AND FERMENTATION OF TOBACCO LEAF PRIOR TO MANUFACTURE}

Selection of leaf. Treatment and Blending. ObJects and methods of Fermentation. Action of microbes. 



\section{REHANDLING AND FERMENTATION OF TOBACCO LEAF PRIOR TO MANUFACTURE}

We have seen how the tobacco passes from the grower to the manufacturer or leaf dealer. Before it is fitted, however, for manufacture into cigars or other finished products the leaf must go through many processes, the most important of which is fermentation. These processes, which are usually known as rehandling, are carried out in special buildings which are called leaf houses and stemmeries. The procedures in different leaf houses may vary somewhat, but the general principles and objects in view are the same in all. Moreover, the treatment is different, according to the ulterior disposition of the leaf, $i$. e. whether intended for cigars, pipe smoking or other product.

The general treatment as carried out in large establishments is about as follows:

The leaf as soon as it is received whether in casks, cases, bales, or otherwise is opened up and inspected in the casing room. Large concerns which manufacture or deal in cigar and other kinds of leaf, sort out the different kinds suitable for each class of product, i. e. wrappers, fillers, binders, cigarette leaf, plug leaf, 
etc. These are distributed to either special houses or departments. The tobacco leaf when first received is usually dry and brittle. The bundles are carefully opened up and the leaves loosened and spread out on large trucks where they are sprayed with water. When the leaf has soaked the water and is pliable it undergoes a sorting which is done by selecting leaves from different cases or even bundles of leaves and in a general way arranging them so that each truckfull represents a blend of the different kinds of leaf which are suitable for the purpose in view. These sorted packages are then roughly fastened together and after being again sprinkled thoroughly are sent to the "sweating" room to undergo fermentation which may last several weeks. The temperature of this room must be carefully regulated and is usually kept at about $90^{\circ} \mathrm{F}$.

The selection and blending of the different kinds of leaf is most important. It requires accurate and expert knowledge in choosing leaves and kinds possessing different strengths and other qualities and in combining them in such proportions that the final effect of the blend gives just what is required.

It is particularly in this expert treatment of the leaf before manufacture that the greatest advance has been made in the tobacco industry. 
The smoker has the advantage and satisfaction of knowing that not only does he get the benefit of improved scientific knowledge and sanitary conditions by which anything that might be harmful or undesirable is removed, but that handling the leaf in large quantities effects great economics and procures for him the benefit of choicest selected grades at a reduced cost.

It may be said here incidentally that leaves of the very best tobaccos which are defective merely in size, or color, etc., are put through exactly the same processes as the choicer quality leaves, and are used in the manufacture of the popular priced machine-made "little cigars" and "cheroots."

It will be necessary now to digress for a short time and consider what happens during the process of fermentation.

\section{Fermentation of Tobacco}

The fermenting of tobacco leaf has for its principal objects, (1) the removal of acrid matters, (2) the fixing of the color, and (3) the production of flavor. Fermentation can only take place under suitable conditions of heat and moisture, and is essentially a chemical process during which certain organic compounds stored in the plant are split up and others formed. 
A certain amount of fermentation takes place in the curing houses during the "yellowing" of the leaf after it has been harvested, but as we have seen the main process of fermentation does not occur until it is "rehandled" by the manufacturers.

The general opinion held at present as the result of investigation is that the transformations which are effected in the leaf are purely the result of chemical processes. As the plant slowly dies and decomposes special ferments are produced. These ferments set up an oxidization process which splits up the complex organic compounds which still exist in the leaf cells. The starch in the plant is changed into sugar which is slowly consumed. There is a decrease in the fats and gummy substances, also in nicotine and nitrogenous compounds, and there is a formation of certain organic acids such as malic, citric and oxalic which are essential in the production of flavor. Briefly it may be said that the process is an attempt by the plant to prolong its existence by feeding on its own substance, by drawing on its own reserves and on its own structure for the food which its cells no longer receive through the natural growing process. When the struggle is over the "fermentation" is complete. The necessity for maturing tobacco has long been 
known but the exact nature of the changes that take place during the process were not understood. Since the discoveries of Louis Pasteur regarding the part played by bacteria in general fermentative processes it has been generally claimed by bacteriologists that the changes wrought in the leaf and the production of flavor are solely the work of bacteria. Although this view has not been proved it has never been fully disproved, and there appears to be no doubt that the microbes known to exist in the leaf during the fermentation process play an important part in the process. Fermentation can only take place as stated under suitable conditions of heat and moisture and these are the conditions which favor the development of microbes and enable them to work. The results obtained are probably partially due to chemical action and partly to bacterial action, the two being complementary to each other.

In 1899 Suchsland, a German scientist, startled the tobacco world by asserting that the flavor of tobacco was in no way due to the effects of the soil and climate where it was grown, but was solely due to microbic action, and that the specific flavor and aroma of any given tobacco could be artificially produced by the cultivation of selected bacteria and allowing the tobacco to cure and ferment under their ac- 
tion. He conducted a series of experimental investigations in which he searched for and isolated the specific microbes found in the best West Indian tobacco. From these he made artificial cultures and introduced them into heaps of inferior, coarse German tobacco which was undergoing curing. His results were such that the smoking quality of the leaf was entirely changed. It could scarcely be distinguished from the best Cuban tobacco and experts and connoisseurs failed to identify the product as German tobacco. A company was formed to exploit the new ideas commercially, but it does not appear to have met with success. Other investigations failed to obtain Suchsland's results and extensive investigation in the Agricultural Experimental Station in the United States have not up to now produced any results confirmatory of the theory.

We can now proceed to follow the course of the tobacco in its peregrinations through the leaf house.

On their return from the first fermentation the bundles go to the picking department. Leaves which are damaged or unsuitable in any way are here picked out and put aside to be used in the cheaper grades. The leaves are then subjected to a thorough cleaning to remove particles of sand, clay, etc., packed tightly in 
bundles and returned to the sweating department to undergo further fermentation and to allow for a thorough interchange of the aroma of the different blends. In due course the bundles pass to the stemming department for the removal of the midribs which usually form nearly one-third of the entire weight. The resulting half leaves are then arranged in piles of 50, each pile forming a "book."

From the stemming department the books pass to the drying room where any superfluous moisture is removed by hot air currents.

From the drying room the books pass to the ordering room where they undergo inspection for color, size etc., and subjected to further treatment if necessary. Here they are finally packed in cases and stored for several months to allow perfect and uniform blending after which they are ready for shipment to the factory. Filler leaf for the finest cigars may stand in these cases for two or three years.

Leaf which is intended for chewing or pipe smoking is not subjected to so great an elaboration of processes as cigar leaf, as the matters of uniformity of color, and delicacy as well as individuality of aroma are not of such great importance. Usually such tobacco leaf is fermented in bulk, and the removal of the stems is done before the principal fermentation. 
After the preliminary selection of varieties, sorting, stemming and cleaning, the leaf is dipped into large vats containing flavors; and after drying are subjected to steaming. They are then packed away in bulk in the sweating department where they slowly ferment until required for use. These "bulks" or stacks may contain many tons of leaf. They require constant turning over, etc. Indeed it may be said that every step in these processes requires constant care. Temperature, moisture, length of exposure, etc., must all be carefully seen to. Otherwise the tobacco will spoil.

In the case of tobacco leaf intended for export trade rehandling consists mainly of stemming and removal of moisture. This is done before shipment in order to reduce the weight as customs duty is levied in accordance with the weight of the imported packages in the countries importing.

\section{REFERENCES}

U. S. Depart. of Agric. Farmers' Bulletins 6 and 60.

LAUREUT, L. Le Tabac, sa culture et sa preparation, production et consommation. Paris, 1900. Bouant, E. Le Tabac; culture et industrie. Paris, 1901. 
Boekhout UNd de VRies. Uber Tábacfermentation. "Centralbl. f. Bakter," 1909. 2 Abteil. Vol. 24, p. 496.

Loww, O. Sind Bakterien die Ursache der Tabakfermentation? "Centralbl. f. Bakter," 1909. Vol. 6, p. 108.

Killebrew and Myrick. Tobacco Leaf. Part I. New York, 1897.

Suchslanl, E. Bobachtungen über die Selbsterwärmung des fermentierenden Tabaks. In "Festschrift 200-Jahr Jubel. d. Verein. Friedrichs Universit." Halle-Wittenberg, 1894.

WoLF, Јаков. Der Tabal und die Tabakfabrikate. Chapter IV. Leipzig, 1912.

Hoagland, J. G. The Tobacco Industry. In Quarterly of the Nat. Fire Protec. Assn., 1907. Vol. 1, Nos. 2 and 4.

J ACOBsteIn, M. The Tobacco Industry in the U. S. Chapter II. New York, 1907. 



\section{CHAPTER IX}

\section{MANUFACTURED PRODUCTS OF TO- BACCO IN THE UNITED STATES}

Statistics of pRoduction and consumption. Amount of capital invested, etc. 



\section{MANUFACTURED PRODUCTS OF TO- BACCO. GENERAL REMARKS}

The importance and magnitude of the tobacco manufacturing industry in the United States will be best understood from a consideration of the following statistics taken from the latest available government records:

(For all Manufactured Products)

Cost of materials used. . (1905) $=\$ 126,000,000$ $(1909)=177,000,000$ Value of the product. . (1905) $=331,000,000$ $(1909)=417,000,000$ No. of establishments. (1905) $=\quad 16,828$ $(1909)=\quad 15,822$

No. of persons employed, more than one-third being wo$\begin{aligned} \text { men } \ldots \ldots \ldots \ldots(1905) & =160,000 \\ (1909) & =197,000\end{aligned}$

The figures are given in round numbers. The total capital invested in this industry is between $\$ 300,000,000$ and $\$ 400,000,000$.

There are more than one and a quarter millions acres in the $U$. S. under cultivation of tobacco which yields a crop at present approximating to 1,000 million lbs. of leaf annually.

The industry shows an absolutely increasing condition in every particular at each census. 
During the past 45 years the value of the product has increased more than $\$ 300,000,000$.

In addition to the trade in manufacturing in the U. S. there is the export trade principally in unmanufactured leaf. This amounts at present to about $\$ 54,000,000$ annually. The price of export leaf has been continuously increasing despite of the fact that the production of leaf abroad is increasing. Thus in 1886 the average export price of leaf from the U.S. was $81 / 2$ c per lb. In 1914 it was more than $12 \mathrm{c}$.

The following statement shows at a glance the marvelous increase in the tobacco industry:

Comparative Statement of Manufactured Tobacco in the U.S. (all products)

Capital No. of persons Value of invested. employed. product.

$\begin{array}{lrlrrr}\text { Year } 1880 & \ldots \ldots \ldots \ldots \ldots & \$ 39,000,000 & 86,000 & \$ 126,000,000 \\ \text { Year } 1890 & \ldots \ldots \ldots \ldots \ldots & 90,000,000 & 117,000 & 195,000,000 \\ \text { Year } 1900 & \ldots \ldots \ldots \ldots \ldots & 111,000,000 & 142,000 & 264,000,000 \\ \text { Year } 1905 & \ldots \ldots \ldots \ldots \ldots & 324,000,000 & 159,000 & 330,000,000 \\ \text { Year } 1909 . \ldots \ldots \ldots \ldots \ldots & & 197,000 & 417,000,000\end{array}$

In addition to the number of persons employed in manufacturing we must take into account those employed (as well as the capital invested) in the agricultural and distributing ends.

The export manufacturing trade is not important, being only valued at about 3 million dollars annually. 
The value of the home manufactured products which in 1905 was shown at $\$ 330,000,000$ is distributed as follows.

Cigars . . . . . . . . . . . . . \$198,000,000 Cigarettes .............. 16,000,000 Chewing and smoking tobaccos . . 109,000,000 Snuff . . . . . . . . . . . $\quad \mathbf{6 , 0 0 0 , 0 0 0}$ Other products ........... 1,000,000

Total . . . . . . . . . . \$330,000,000

For the increase in the present value of the product these figures would be proportionately increased.

In the year 1913 the United States exported about $\mathbf{3 5 0}$ million $\mathrm{lbs}$. of unmanufactured tobacco leaf, and in 1914, 449 million lbs. This was distributed as follows:

To Great Britain and Ireland 174 million lbs. To Canada ............ 17 "6

To France ........... 55 "6 "

To Germany .......... 32 " "

To Italy ............. 45 "6 "6

To Netherlands ........ 28 "6 "

To Spain ............ 17 "6 "6

To Japan ............ 16 "6

To China ............ " 11 "

To Belgium ........... 11 " "6

To Africa, Australia, etc. ... 43 "6 " 6

Total ...........449 66 "6 
The largest export manufacturing trade was to Asia, the cigarettes exported there having a value of $21 / 2$ million dollars.

The consumption of manufacturing products of tobacco in the U. S. has increased continuously since 1863 when it was $1.6 \mathrm{lbs}$. per head to the present time when it is $51 / 2$ lbs. per head of the total population. This works out at about $16 \mathrm{lbs}$. per head for each male over 16 years. The consumption of tobacco in the U. S. is higher than in any other country and has increased more rapidly. For the past 40 years the consumption per head in U. S. has increased $24.0 \%$; in England $56 \%$; in France $24 \%$; in Germany 23\%. From this fact different deductions might be made. It may be that the Americans smoke more because they are fonder of tobacco than Europeans; or because they get better and cheaper tobacco; or because they can better afford to buy tobacco. The greatest percentage of increase in the United States is in the consumption of cigars.

The manufactured products are classed as (1) cigars, (2) pipe smoking and chewing tobaccos, (3) cigarettes, (4) snuff. To each of these separate chapters will be devoted.

(For references see Chapter $X V$ ) 


\section{CHAPTER $\mathrm{X}$}

CIGARS. HISTORICAL AND GENERAL FACTS

History. Statistical information regardING THE CIGAR BUSINESS IN THE United States 



\section{CIGARS. HISTORICAL AND GENERAL FACTS}

When the Spaniards landed for the first time on American soil they found the natives smoking the rolled-up tobacco leaves, that is a cigar. For a cigar is nothing more, four centuries having made little change in the Cuban cigar. The word cigar is most probably derived from the Spanish word cigarer-to roll. Other derivations are given, but this seems etymologically the correct one; and we will rest content with it. In Spanish America to the present day the custom of smoking tobacco in the rolled form, either as cigars or cigarettes, prevails, rather than the custom of smoling in pipes which was the method of the northern aborigines from whom the English colonists adopted it. Smoking was introduced into Spain in the cigar form and into England in the pipe fcrm. Cigars, however, at the present time, both in North and South America, form the principal item in the tobacco account of the people; we shall therefore enter somewhat fully into matters concerning their manufacture, etc.

Although, as stated, it is in the cigar form that smoking was introduced into Spain, it was not till about 1790 that cigars were used generally in Europe. A factory for the manu- 
facture of cigars was established at Hamburg in 1796. The custom did not spread rapidly and did not reach any considerable proportion in England till about 1830 when the high duties were considerably reduced.

Cigar making has always been a staple industry in Cuba. It was there when the Europeans landed and it is there still. Its record is unbroken. There was always a greater or lesser exportation to Europe and elsewhere.

\section{Tha cigar business of ThE U. S.}

Of the various manufactured products of tobacco leaf, the cigar trade is the most important in the U. S., its value being greater than that of all other tobacco products combined.

The magnitude of this branch of the tobacco business may be gauged when we state that at . the present time there are made annually in the U. S. cigars of all kinds to the amount of about $81 / 2$ billions. The Census Bureau Report for 1912 shows that for that year the number of full-sized cigars made and on which tax was paid was in round numbers 7,500,000,000, and of "little cigars," that is under the regular size, about 1,000,000,000. These figures are certainly stupendous, particularly when we consider that, in addition, at least several hundred 
more were imported and that only about $\mathbf{2 , 0 0 0 , 0 0 0 ~ w e r e ~ e x p o r t e d . ~ U n c l e ~ S a m ~ e v i d e n t l y ~}$ likes to smoke cigars.

To make these cigars requires a consumption of 136 million lbs. of cigar leaf. Nearly 50 million lbs. of this is imported at a gross cost (exclusive of duties) of about 35 million dollars, the rest of the leaf is home grown. The principal imports are from Cuba. In 1912 we imported cigar leaf from Cuba in amount nearly 23 million lbs. and in 1913 this increased to over 27 million lbs. valued at more than 16 million dollars. The imports of East Indian (Sumatran) leaf varies from 6 to 8 million lbs. and costs from 7 to 8 million dollars.

Although the amount of imported leaf used in cigar making shows a steady increase, being now more than $\mathbf{5 0 \%}$ greater than a decade ago, yet the proportion of foreign leaf to homegrown leaf in the whole manufacture shows a steady decrease. This speaks well for the improving quality of American grown leaf.

There are in the United States about 26,000 cigar factories, both large and small. The large number of establishments is due to the fact that cigar making is still to a large extent a handmaking industry. About 135,000 persons arc directly employed in the manufacture, nearly half of whom are women. The capital engaged 
in the business is reported as 150 millions and the value of the product 200 million dollars annually. The actual consumer pays about $\mathbf{3 0 0}$ million dollars for the cigars smoked, the difference between the cost of the product and the latter figure being the expense and profit of the retail handlers. The enormous growth of the cigar trade is seen when it is compared with 1860. In that year the annual value of this product was only 9 million dollars. The two states of New York and Pennsylvania are the centers of cigar manufacture. Between them they make nearly half of the entire product, Pennsylvania leading with about two thousand million cigars annually. Florida makes about 300 million. The price paid by the consumer works out to an average of about $4 \mathrm{c}$ for each cigar. 


\section{CHAPTER XI}

\section{CIGAR MAKING}

Hand-made cigars. Machine-made cigars. Classification of cigars. Terms used IN THE CIGAR TRADE 



\section{CIGAR MAKING}

It was inevitable that modern progress should invade and revolutionize the old and slow methods of cigar making; and so it has. Smoking is a sentimental occupation and lends itself easily to romantic associations. A good deal of romance and sentiment still hangs around the hand-made cigar and cigarette. In an up-todate cigar factory, however, the whir of machinery and the precise, regular movements of automatic contrivances give little scope for sentiment.

Up to 1870 cigars were hand-made. All that was necessary was an inexpensive board, a cutting knife, and a block of wood with a stationary knife, known as a "tuck," for measuring and cutting the finished cigar.

About the time stated the "mold" was introduced. The mold is a wooden block about $18^{\prime \prime} \times 6^{\prime \prime} \times 3^{\prime \prime}$, a tool which facilitates the shaping of the "bunch" or filler part of the cigar and presses it into shape. This mold is now used in most "hand-made" cigar factories where the labor is subdivided into "bunch-makers" and "rollers," the latter putting on the binder and wrapper and finishing the cigar.

It is the introduction of practically automatic machinery, however, which is revolutioniz- 
ing the cigar-making business, and slowly but surely driving the "hand-made" cigar into the position occupied by the "hand-made" cigarette. And the writer cannot see why this should not be so. As it has been said, there is much sentiment about hand-made cigars. But common sense seems to be on the side of the machine. We quite understand the difficulty of killing old prejudices and time honored customs; but it is difficult to understand how the flavor or quality of a cigar filler can be different whether it is pressed into the shape by a machine or by the hand of a workman; or what the precise improvement is when a wrapper leaf is put on and licked by a workman rather than by a clean machine under perfect sanitary conditions. However, sentiment still persists. Imaginary, or perhaps real, charms are ascribed to the hand-made goods and the smoker is willing and even wishful to pay a higher price for his fancy. The result is that the small factory is still predominant. It depends more on labor than on capital. But the large factories have an immense production. The condition will be best shown by stating that in less than 1 per cent of the cigar making establishments of the U. S. nearly 50 per cent of the entire output is made, or, putting it another' way, nearly three-fourths of all the licensed cigar factories 
produced less than one-tenth of the product. Of the 26,000 establishments in the U. S. only in 2 is the annual output more than $\mathbf{5 0}$ million and in 27 the output runs from 25 to $50 \mathrm{mil}-$ lion. Pennsylvania establishments, principally in Philadelphia, produce $28 \%$ of the entire U. S. cigar output; New York State, principally New York City, comes next with about 20\%; and Ohio, principally Cincinnati, third with about $8 \%$.

For machine-made goods the principal machines used-are the bunch rollers and the suction table. The former rolls the bunch of filler leaves and presses them into shape. The suction table is used for wrapping the cigar. The operator places the wrapper leaf on a perforated plate. By pressing a foot lever a vacuum is created beneath this plate which holds the leaf smooth and snug against the table. The perforated plate is exactly the form which the wrapper must be to properly fit the cigar. It is easily cut around and trimmed to shape. The bunch from the bunch roller is then quickly encased in the wrapper. Human labor is necessary only to feed the machines and to spread the wrappers. 25,000 bunches can easily be wrapped in a week at a cost of $\$ 6$ to $\$ 9$ for labor (principally female) and the upkeep of the machine. This in labor 
alone would formerly cost as much as $\$ 75.00$. In the smaller "hand-made" factories, the method of procedure is about as follows: The leaf on receipt is opened and moistened. The "filler" leaf is separated from the wrapper. The filler leaf is made up into "books," a "book" being a bunch of leaves suitable for one cigar. The loose books are then allowed to ferment for a week or so when they are ready for use. The bunchmaker selects and arranges his leaves from each book, selects his binder and rolls the whole into cigar form. If a mold is used he puts the bunch in a matrix of the mold and fastens down the cover until the leaves are pressed into shape. They then go to the wrapper man and are wrapped either by machine or by hand, according to the class of goods. The wrapping is begun at the lighting end and finished at the point which is called the head. After trimming to gauge, the cigar is ready for inspection and classification according to color, etc., and for banding.

Cigars according to their manufacture are classed for trade purposes in various ways. The trade nomenclature embraces the following descriptions: Cigars, little cigars, all-tobacco cigars, stogies and cheroots. 
Cigars proper have many subdivisions:

(1) Imponted Cigars. This term is usually confined to cigars made in Cuba, and does not include Porto Rican or Philippines.

(2) Porto Rico Cigars. ? Used for cigars made

(3) Phirippine Cigars. in those places.

(4) Clear Havanas. This term denotes a cigar made by hand in the U. S. of Cuban tobacco exclusively and in the same style as in Cuba.

(5) Seed and Havana. Up to about 50 years ago there were no clear Havanas made in the U. S., the best produced being a combination of Havana leaf and leaf grown in the states from imported Havana seed. Hence the term which ordinarily means an American made cigar, the filler being wholly or partly of Cuban tobacco and the wrapper, a domestic or Sumatran leaf.

(6) Domestic Cigars. This term is used for cigars made in the $\mathbf{U}$. S. in contra-distinction to imported cigars.

(7) Nickes Goods. Ordinary 5c cigars made either entirely of domestic tobacco or with a Sumatran wrapper, and usually made partly or wholly by machine. It also usually includes "segundos" or 
"seconds," i. e., cigars of a better type made to sell at higher prices but which on account of some defect are rejected on inspection. Sometimes clear Havanas made of scrap filler and inferior wrapper are included. These cigars have a vast variety of designations and make up the general stock of most cigar stores. The cost of production does not usually exceed $\$ 20.00$ per thousand and they sell to dealers at from $\$ 25.00$ to $\$ 30.00$

(8) Stogies, Tobies, Etc. Cheroots. 'Cigar shaped rolls of cheap domestic tobacco made quickly by machine, and of various sizes. Cheroots are open at both ends. The filler of stogies is usually a western grown leaf of full size, but rough quality. They are manufactured principally in Louisville, Cincinnati, Pittsburgh, Wheeling, etc.

One of the large tobacco companies operates about 25 large cigar factories in various centers of the U. S. Here are made all classes of domestic cigars, but all are made under the same conditions of sanitation, economic handling and strict supervision. The leaf is prepared, selected, fermented, blended, etc., in the company's own special leaf houses and is des- 
patched to the various factories as needed. All the better class of domestic cigars are handmade, machinery being used in making the cheaper grades. There are special factories for the making of "little cigars," of which a vast number are made on account of their popularity. These include the package goods and those put up in cardboard boxes of which such brands as "Virginia Cheroots" and "Royal Bengals" are types. By the terms "little cigar" the trade recognizes all cigars under the regular standard size and which weigh less than 3 pounds per thousand. In some "little cigar" factories these little cigars are not made from inferior leaf. They are made usually from the small leaves of the tobacco intended for higher priced goods, but which on account of faulty size cannot be used. The leaf is, however, cured and prepared in exactly the same way. In addition the "sicrap" or waste portions of the high priced leaf is used for fillers for little cigars. The little cigars of this type are usually of first-rate quality and on account of their small cost give excellent value to the smoker.

\section{Cigars. Mrscellaneous}

There are a good many terms used in the cigar trade to denote color, size, quality, etc., which smokers should know the meaning of. 
Most of these terms are Spanish, because the cigar trade was for a long time confined to Cuba.

Terms used to denote the quality of cigar leaf Desecro. The finest quality; the top leaves of plant; best because they have received most sunshine and dew.

Desechito. Good leaves but inferior to desecho.

LimRA. Good leaves but small in size; the smaller top and bottom leaves.

InJuriado. Injured leaves; root leaves soil stained and injured by insects.

\section{Terms used to denote color}

Note: The color term refers to the wrapper only. Many smokers judge the mildness or strength of a cigar by its outside color. This is a fallacy. The wrapper constitutes only about 2 per cent of the cigar weight. Moreover color is no criterion of strength. The darkest cigar may be and usually is very mild. The color is due (1) to the soil, (2) to the age of the plant when cut, and (3) to the length of time of curing 'and fermentation. As a general rule the lighter the color the more inferior and immature is the tobacco. Cigar smokers should remember this. 
Claro or Clara. Very light colored. The lightest shade known in selected leaves.

Colorado. Red; medium in color.

Colorado Clara. Light Brown.

Colorado Maduro. Dark Brown.

Maduro. Ripe; very dark, almost black in color.

Terms used to denote size and shape

Conchas. Shell; cigars so marked are $414^{\prime \prime}$ long.

Concha Fina. A first quality Concha.

Concha Especial. Finely finished and somewhat larger than a Concha.

Londres. London. Specially made for the London market and on account of its shape and length.

Regarias. A cigar of a finer grade of tobacco than is used in Londres or Conchas. Damas. Ladies; small cigar about $\mathbf{3}^{\prime \prime}$ long. Panatelas. A long thin cigar that has been heavily pressed.

Non plus ultra. A large handsome cigar made from the finest tobacco.

Escepcionar.es. Exceptionally large sized cigar.

OPERA. A small after-dinner cigar about 31/4" long.

Princesses. Like the Opera, but thinner. Coquetras. Flirt; 31/2" long. 
Brevas: A short, thick cigar.

Noblesse. The largest and most expensive cigars.

In addition to the above there is a multitude of trade names, such as Club House, Hoffman House, Rothschilds, Invincibles, Perfectos, etc.,. etc. Some of these terms merely denote particular brands put out by certain makers and to distinguish their products. The Spanish terms refer to the cigar itself and not to the maker. They may be used by any maker, and no longer refer to any standard of excellence. (See references end of Chapter $X V$ ) 


\section{CHAPTER XII}

\section{CIGARS AND THEIR QUALITIES}

Qualities of cigars and cigar leaf. IMported cigars. Havanas.

Domestic crgars. 



\section{CIGARS AND THEIR QUALITIES}

- A cigar consists essentially of three distinct parts: the body or inner part called the filler; the covering of the filler which is called the binder; and the outside finishing cover which is called the wrapper. Cuban cigars, however, consist of filler and wrapper only.

Except in the case of cigars made in Cuba the wrapper leaf is usually of a different class of tobacco from the rest of the cigar, as the qualities to be fulfilled by each part is different. The qualities required in a cigar must be viewed both from the smokers' and the manufacturers' standpoints and the leaf must be such as to conform to these qualities. Thus the smoker is concerned with the burning quality, the taste, flavor, aroma, color, general appearance and strength of the cigar. The manufacturer in addition to seeking leaf that will answer the smokers' requirements also has an eye to economy and requires the leaf to have qualities regarding size, weight, texture, etc. Therefore, in the best cigar leaf the following qualities are more or less essential: (1) good color, (2) fair body, (3) a continuous pleasant aroma, (4) fine texture combined with a certain toughness, (5) small ribs and veins, (6) good combustion so that it will hold fire for 4 or five minutes. 
The burning must be free and even with a white or whitish-brown ash which remains intact until cigar is three-fourths smoked, (7) good size of leaf, (8) must be elastic and souple, must not be brittle, (9) it must be free from spots and light in weight.

Some of these qualities are essential in filler leaf; some in wrapper leaf. Thus the color of filler leaf does not matter; neither does the aroma of the wrapper the essential qualities of which are color, lightness and elasticity.

The cigars consumed in the U. S. are either (a) Imported or (b) Home Manufactured.

\section{(a) Imported Crgars}

The most important of the imported cigars are those that come from Cuba, Porto Rico and the Philippines.

Up to the time of the Civil War cigars were imported principally from Germany and Cuba and the value was about $41 / 2$ million dollars annually. High import duties have, however, altered this and the number of imported cigars is nearly 90 per cent less than formerly. The value of the import has not, however, fallen so much, that is to say only the higher grades of cigars are imported. The value of cigars now imported does not exceed 3 million dollars annually and they are principally Cuban. 


\section{Cuban, or so-called Havana, Cigars}

As the strictest laws are enforced in Cuba against the importation of tobacco, it follows that all genuine so-called Havana cigars are made of Cuban tobacco. The Havana Tobacco Co. controls about 260,000 acres of the best Cuban tobacco land and has $\mathbf{2 5}$ factories in the City of Havana. Here Havana cigars are made in all grades from those which can be bought at 2 for $25 \mathrm{c}$ to those which cost $\$ 2.00$ each. The high priced are very limited in quality, being made from tobacco grown in specially favored districts. The Province of Pinar del Rio produces 70 per cent of the whole Cuban crop, and includes the celebrated District of Vuelta Abajo in which the finest cigar tobacco in the world is grown; the Provinces of Havana and Santa Clara each produces about 13 per cent of the Cuban crop. Havana Partidio leaf is of very fine quality and is used principally as wrappers of cléar Havanas. Havana Remedios leaf comes from Santa Clara, has a high flavor, rather heavy body and is used mostly for fillers.

The very finest Havana cigars never leave Cuba, for the merchant keeps them for his own use. He is a smoker before a trader. The crop of the very best Vuelta Abajo tobacco is so small that not more than about 30,000 cigars can be made from it. These are kept for pri- 
vate purchasers and none go on the market. The finest Havanas are of an even tint of rich dark brown, free from all stains and spots, burning freely to a white or whitish-brown ash, and holding fire for 4 or 5 minutes. Altogether the District of Vuelta Abajo produces about one-quarter million bales of leaf annually and about one-tenth of this is high class and produces up to 20 dollars per $1 b$. on the spot.

As stated previously, Cuban cigars have no binder. They consist of filled and wrapper only and are all hand-made. The unique position which these cigars have held for so long is due not only to perfect curing and blending of the leaf, but also to the superior skill of the Cuban workmen who are the most expert cigarmakers and blenders in the world, and who in the best factories are allowed to take all the time they need in making the cigar. Some of these "Tabacqueros" have been making the same brand of cigar for 20 years or longer.

Of the total annual output of Cuban made cigars, England takes about 40 per cent, the U. S. about 25 per cent and Germany 13 per cent. In 1913, the U. S. imported $659,358 \mathrm{lbs}$. of cigars and cheroots from Cuba valued for $\$ 3,999,410$. 


\section{Porto Rico Cigars}

From Porto Rico the U. S. ships about 125 million cigars annually.

\section{Phimippine Cigars}

The laws in force between the U. S. and the Philippine Islands, governing the tariff, provide for the importation annually from the Philippines to the U. S. free of import duties, of cigar wrapper leaf and filler leaf mixed or packed with more than 15 per cent of wrapper leaf, not in excess of $300,000 \mathrm{lbs}$; of filler leaf alone not in excess of $1,000,000 \mathrm{lbs}$.; and manufactured cigars in number not exceeding 150,000 ,000. The shipping must be direct.

As the Philippine leaf is excellent and labor there is cheap, the U. S. smoker is thus enabled to get a very good smoke at a small cost. The full number of cigars allowed at least is imported. In 1913 the importation of Philippine cigars and cheroots to the U. S. was $1,641,832$ lbs. valued at $\$ 2,296,823$.

\section{Home Manufactured Cigars}

For the home manufactured cigar trade the leaf used is either imported or home grown.

Imported cigar leaf comes principally from Cuba, Dutch East Indies (Sumatra, Java, etc.), Porto Rico, Mexico, Brazil, and the Philippines. 
Imported Cuban leaf is used both as fillers and wrappers. The U. S. as already stated imports about 26 million lbs. annually. The leaf varies in length from $\mathbf{8}^{\prime \prime}$ to $18^{\prime \prime}$; is a rich brown color, and its principal characteristic is its fine flavor and aroma, which is unequalled by any other tobacco in the world.

The Sumatran leaf is perhaps more important in the U. S. cigar trade than the Cuban leaf. It is used exclusively as wrappers, on account of its fine light brown color, its elastic texture and light weight. The genuine imported leaf is much less in weight than that grown from Sumatran seed in Florida. About 2 lbs. of imported Sumatran leaf will wrap 1,000 cigars. Its length is usually from 14 to 20 inches and the U. S. imports annually about 7 million lbs., valued at about 5 million dollars. The use of Sumatran leaf as a wrapper for home-made cigars has increased remarkably in the last quarter century. In the quinquennium ending 1885 the number of such cigars was 34 millions. In the last quinquennium the number exceeded 2,000 millions.

The Sumatran leaf has little aroma or flavor and its value is for appearance only. The average prices paid by the United States for imported cigar leaf in 1914 was: for leaf suit- 
able for cigar making, $127 \mathrm{c}$ per $\mathrm{lb}$.; for "other leaf," 50.44c per lb.

\section{Other Imported Cigar Leaf}

Since the introduction of tax-free manufactured cigars from the Philippines the importation of leaf has declined.

Mexican leaf is used as a substitute for Cuban, to which it is inferior.

The imports of cigar leaf tobacco from Porto Rico and Brazil are relatively unimportant.

\section{Cigar Leaf Tobacco Grown in the U. S.}

The home grown tobacco leaf used in the cigar manufacturing trade of the $U$. S. is grown principally in the states of Connecticut, New York, Pennsylvania, Ohio, Wisconsin, Florida, Georgia, and Texas. The Connecticut leaf is used for wrappers and binders. The Ohio and Pennsylvania leaf almost exclusively for fillers. Wisconsin produces binder leaf particularly. The leaf grown elsewhere is used mostly as wrappers. It is usual, however, to use the imported and Sumatran leaf as wrappers for all high class home-made cigars.

The finest American grown wrapper leaf is raised in Connecticut. The best known brands are known as Connecticut Seedleaf and Connecticut Broadleaf, both varieties raised orginally 
from imported Havana seed. The leaf is destitute of thick fibers and has a fine texture. They run from 14" to $26^{\prime \prime}$ in length, giving good wrapping capacity.

The Pennsylvania leaf is also classed as Seed and Broadleaf. It is about the same size as the Connecticut, but does not equal it in quality. The principal varieties in Ohio are the Gebhardt, Zimmer, Spanish, and Little Dutch. These do not usually éxceed $20^{\prime \prime}$ in length. Florida cigar leaf is usually small, running from $10^{\prime \prime}$ to $14^{\prime \prime}$ in length.

(For references see Chapter $\mathrm{XV}$ ) 


\section{CHAPTER XIII}

\section{PIPE SMOKING AND CHEWING TOBACCOS}

Qualities Required. Description of Kinds.

Perique tobacco. Statistics. 



\section{PIPE SMOKING AND CHEK: TOBACCOS}

For pipe smoking mixtures the tobacco liaf used is of various kinds. Preferred strains of leaf from Virginia, North and South Carolina, Tennessee, Kentucky, Maryland, and East Ohio, to which is added sometimes Turkish, Latakia, Perique, and a little Havana. The blend is made while the tobacco is in leaf form, portions of the desired kinds being assembled in accordance with a formula followed by the manufacturer. The leaf is then put through the required mechanical processes.

The qualities necessary in pipe smoking tobaccos are that it must burn evenly, slowly, smoothly and thoroughly; it must have an agreeable aroma; it must not cause a burning or acrid sensation in the mouth when smoked; it is desirable that its nicotine contents should be low. Appearance is not of any consequence, but the manufacturer looks for leaf that, in addition to the above qualities, is free from gumminess as this interferes with granulation and cutting; also that the leaf may be a good absorbing kind in order that it may imbibe the juices with which this class of manufactured tobacco is treated both for chewing and pipe smoking. 
As the taste of smokers with regard to the flavor and aroma of pipe tobacco varies considerably, some desiring a strong, others a mild or light tobacco, this must be taken into account by the manufacturer and the blends graded accordingly.

Pipe smoking tobaccos are distinguished according to the different mechanical processes used in their production. Thus there are (1) Granulated, (2) Plug-cut, (3) Long-cut, Finecut, etc. In former days it was customary for smokers to buy their tobacco in the roll or twist and cut and manipulate it themselves. This custom has, however, passed away almost entirely in the U.S. It still survives to a large extent in Europe where smokers prefer their tobacco moist. In the U. S. pipe smoking tobacco is usually cut and ready for the pipe and sold in packages or cans.

Granulated is tobacco that has been flaked by breaking or cutting machines with blunt teeth or saws and then passed over a series of oscillating sieves of graded mesh.

Plug-cut or Cut-plug is first made into plugs by pressure. These plugs are then cut into thin slices convenient for crumbling. The slices are put up in packages in which form the smoker uses it. Special forms of cut-plug are, bird's-eye, short-cut, cube-cut, straight-cut, 
curly-cut, wavy-cut and cavendish-cut; the name being determined by the shape of the cut slices. "Navy-cut" is a particular kind of plug which was originally prepared directly. by shipmen.

Long-CUT tobacco is leaf cut into long shreds. It differs from plug-cut in not having been pressed into solid plugs before cutting.

Fine-cut is finer and shorter shreds than the long-cut, and the tobacco used is usually of a less gummy kind.

Other varieties known in the trade are:

German Smoking. A coarse-grained, heavy tobacco with strong flavor. It is a coarse granulated tobacco.

Struss. A fine shredded or powdered tobacco used principally in the mining camps of Pennsylvania.

Scrap. Smoking tobacco made up from cigar clippings and cheap cigar leaf of the filler and binder type.

\section{Perique Tobacco}

Perique tobacco is a specially dark, rich variety having special qualities which render it desirable as a component in pipe smoking mixtures, or for straight smoking. Genuine Perique is grown and prepared only in the Parish of St. James in the State of Louisiana 
by the descendants of the old French Colonists. The properties which it possesses are essentially due to the peculiar method of curing and fermentation and not to any peculiarity in the leaf itself. It is the only tobacco in the United States that is grown and put in its final condition for the consumer by the farmer. It is said that the output of genuine Perique is small, being well under 50,000 lbs. annually. But there is a good deal of substitute Perique sold in lieu of the genuine kind.

The tobacco is raised on a black, deep, exceedingly rich soil. The leaf is medium in size, about $18^{\prime \prime}$ long, and a rapid grower. The stem is small, the fiber tough and gummy.

In curing no artificial heat is used. The leaf is hung in sheds for about 10 days. It is then stripped into half leaves. These are taken in bundles of about 20 each and converted into rough "twists." A dozen or so "twists" are packed in a box $11^{\prime \prime}$ square the weight being about 50 lbs. The contents of the box are then submitted to a pressure of about $7000 \mathrm{lbs}$. for at least 24 hours. The tobacco is then taken out and the twists again opened up. The leaves are exposed to the air and sunlight until an exudate appears on them and is reabsorbed. This is done over and over again for at least 10 days or until in appearance the tobacco 
is quite black. That is to say the curing of Perique is accomplished by allowing it to soak its own juice and then submitting to heavy pressure and repeating this process several times. When the leaf is cured it is made into rolls or "carottes." A cotton cloth 24 " × 18 " is taken and covered with leaves. Others are spread crosswise over these. Then rolled and a thin rope is wound very tightly about each bundle on "carotte." This process like the curing is repeated over and over again. One man can handle about 10 carottes in a day, the weight being about $4 \mathrm{lbs}$. each.

Perique is considered to have a finer aroma than any other pipe smoking tobacco and its presence in a mixture is at once detected by the experienced smoker. It is said to contain only $1 / 4$ of the citric acid, $1 / 2$ of the nitric acid and 6 times as much acetic acid as tobacco cured in air. The resultant aroma is rich and fragrant, and the taste is smooth, delicate and agreeable. It is also claimed that it stimulates the brain without in any way being hurtful to the digestive or nervous systems.

When the carottes are finally made it is usual to leave them under pressure for at least 12 months. The aroma is said to improve as the tobacco grows older. 
It has been stated above that much of the Perique tobacco is a substitute for the genuine. This substitute is made by taking inferior leaf and submitting it to a similar process, i. e., pressure and oxidation repeatedly. The process is abridged but a black tobacco results particularly when certain darkening ingrediants are added. The moral is if you want genuine Perique be sure where you get it, and don't grudge the price.

\section{Chewing Tobacco}

The particular qualities required in leaf for this purpose are toughness, sweetness of taste, and a richness in oils and gums. Suitable leaf having been selected the leaf is cut and moulded into small plugs or "chews" which are put up in boxes for the market. Flavoring essences are of course plentifully used.

As well as plug, chewing tobacco may be of the variety known as twist, the leaves being spun and twisted in a continuous.roll.

The plug consists of a wrapper and filler like the cigar the brighter and better grades of leaf being used as wrappers. Burley leaf and the yellow leaf tobacco of Virginia, Kentucky and the Carolinas are principally used. The substances used for flavoring are liquorice, cane sugar, maple sugar, molasses, and rum, prin- 
cipally. The plugs are packed in boxes of 72 lbs. each, and also smaller boxes of 10 and 12 lbs. each.

The principal centers of the manufacture of pipe smoking and chewing tobacco are Missouri (St. Louis); North Carolina (Durham and Winston); Kentucky (Louisville); New Jersey (Jersey City); Virginia (Richmond) and Ohio (Cincinnati).

There are altogether about 400 establishments employing about 20,000 persons, and the value of the product is over 100 million dollars annually.

This class of products is by its nature more suitable for concentration of manufacture than either cigars or cigarettes. Hence the small number of establishments.

Only about 10 million lbs. of manufactured tobacco is exported.

(See references end of Chapter $\mathrm{XV}$ ) 



\section{CHAPTER XIV}

\section{CIGARETTES}

Statistics. Kinds and where made. IMported Cigarettes. Domestic Cigarettes. Cigarette papers. 



\section{CIGARETTES}

A cigarette according to the meaning of the word is a small cigar. It consists of a roll of loose tobacco wrapped in a case of either paper or tobacco-leaf. In the latter case it is known as an all-tobacco cigarette.

Since the introduction of cigarette making machinery the output of cigarettes in the United States has grown enormously. This will be seen from the following figures which represent the output of cigarettes for the past 25 years:

Number of cigarettes

Year manufactured in the United States.

$1890 \ldots \ldots \ldots \ldots \ldots \ldots \ldots$ 2,000,000,000

$1895 \ldots \ldots \ldots \ldots \ldots \ldots \ldots, 3,500,0 \ldots 00,000$

$1900 \ldots \ldots \ldots \ldots \ldots \ldots \ldots$. $4,000,000,000$

$1905 \ldots \ldots \ldots \ldots \ldots \ldots \ldots, 6,500,0 \ldots 0,000$

$1910 \ldots \ldots \ldots \ldots \ldots \ldots \ldots \ldots, 7,000,000,000$

These figures taken from Government Reports are given in round numbers. They include "little cigars" which form about $15 \%$ of the totals. About one-third is at present exported. In addition to the manufactured cigarettes there is, of course, the large amount of cigarettes made directly by the smoker himself. 
There are only about 500 establishments in the whole $U$. S. engaged in cigarette manufacture and about ten of these manufacture four times as many as all the rest together. There would in fact be fewer factories except for the popularity of certain brands of hand made cigarettes. $95 \%$ of the total output is made in 4 cities, i. e., New York, Dunham, N. C.; Richmond, Va.; and New Orleans. New York City alone manufactures about $60 \%$ of the whole; Richmond about $16 \%$; New Orleans about $10 \%$ and Durham the balance.

Every country manufactures its own peculiar brand of cigarettes. The best known and most popular kinds of cigarettes are those known as Virginian, Turkish, Havana, Porto Rican, Mexican, Russian and Philippine.

The Havana, Porto Rican, Mexican and Philippine cigarettes are usually of the all-tobacco kind-the others being paper wrapped. They are generally made from the cuttings and smaller leaves of cigar leaf tobacco.

Turkish cigarettes are celebrated all the world over. The name is however mostly a misnomer, for nearly all the so-called Turkish cigarettes proper are made in Egypt, Greece, etc., and not in Turkey. In Egypt, however, the best Turkish cigarettes are made from tobacco grown in Turkey (in Europe) which 
is imported, as no tobacco is grown in Egypt. The peculiar flavor of Egyptian Turkish cigarettes is due to special methods known only to the makers there.

The crop of Turkish tobacco, particularly of the better kinds suitable for cigarettes, is small and less than half of it is exported. The supply of genuine Turkish cigarette tobacco is, therefore, strictly limited and does not find its way into ordinary channels. Much of socalled "Turkish" tobacco comes from China, and other parts of Asia. From Turkey, in Europe, the United States annually imports at present about ten million lbs., the actual government figures for 1913 being 10,816,048 lbs. valued at about $5 \frac{1}{2}$ million dollars.

From Turkey in Asia the imports in 1912 were 11,233,546 lbs., and in 1913, 18,955,295, this latter being valued at nearly 5 million dollars. ' It does not follow that all this latter is Turkish. It was probably in large part collected from distant points and shipped from ports in Asia Minor. The imports of Turkish tobacco during 1914 are considerably reduced on account of the war.

One American company which does an immense business in the cigarette line maintains at Cavallo a large establishment for the direct purchase and treatment of its own 
Turkish leaf. This plant handles about 6 million lbs. of leaf annually. The American smoker of home-made Turkish cigarettes has the advantage of knowing that his leaf is genuine and bought economically.

The most valued kind of Turkish tobacco is that grown in the Caza of Yenidji on the Vardar River region in Roumelia.

The Latakia tobacco grown in the hilly part of Northern Syria is also celebrated as a cigarette tobacco. This tobacco has a low nicotine percentage (less than one per cent) and its peculiar aroma is due to its exposure for nearly 6 months to the smoke of the tree known as Quercus Ilex. Very choice parcels of these tobaccos fetch in the open market from $\$ 3$ to $\$ 5$ per 1 b. ; lower grades are bought from 25 c per lb. and up.

The best known grades of cigarettes made from genuine Turkish leaf are the La Ferme of Leipzig and St. Petersburg; the Nestor and Melachrino of Egypt; the Monopol of New York; and the Dubec of Richmond. In the Turkish hand-made cigarette there is no flavoring of any kind. In Europe the Turkish cigarettes are usually made by Greeks who are special adepts at this work.

The paper wrappers are imported from France or Austria. The native cigarette 
makers as a rule blend their own leaf and cut or shred it by hand. An expert workman can make about 3,000 cigarettes per day.

In the United States, Turkish cigarettes are of two kinds, imported and domestic. The imported include those purchased already made from Egypt, England, France, etc. In 1913 the value of cigarettes purchased directly by the U. S. from Egypt was about \$25,000 and from England \$22,000, other countries less. In 1914 the total cost of imported cigarettes (not including those from Philippine Islands) was $\$$ 79,554. The value of such trade is, therefore, not large. The Turkish cigarettes made in the States are termed Domestic Turkish, and are usually hand-made, though not by any means exclusively so. It appears to be nothing more than an idiosyncrasy to consider that a handmade cigarette is better than a machine-made one. As in the case of cigars, other things being equal it would appear that on many considerations, hygienic as wèll as mechanical, the balance is in favor of the machine. However, many still think there is some peculiar talismanic virtue in a hand-made cigarette and are willing to pay a higher price. There is, of course, a pleasure in making one's own cigarettes, but when they are bought made the advantage of hand-making is not very apparent. 
There are many variants of the Turkish cigarette. Besides the common paper wrapped variety some have fillers of Turkish tobacco with Havana or Virginia leaf wrapper; others have mixed fillers of Turkish, Virginia, Havana or Perique, two or more or all kinds being mixed. Each type of cigarette has its own special votaries. Cigarettes of this variety are not, however, so popular in the United States as in other countries where the cigarette is the most pronounced type smoked.

The American cigarette is generally made of Yellow Virginian tobacco and is popular all the world over. The secret of success in good cigarette making lies in the selection and blending of the leaf so that the proper strength and characteristics may be secured. As a general rule no adulterants of any kind are added to the tobacco except in some of the very cheap kinds in which the leaf is sometimes treated with a glycerine solution in order to give it a sweetish taste. The solution is quite harmless.

The machinery for the manufacture of cigarettes has been brought to such perfection that it is quite automatic. The only hand work required is the feeding of the tobacco into the hoppers. The cutting, rolling, wrapping, tipping and packing are all done quite mechanically, the cigarettes being turned out all ready 
for the smoker. In the large factories the processes are under strict hygienic conditions, which is not usually the case in the small workshops where the hand-made goods are prepared. The various machines used in the manufacturing processes are highly complicated and a detailed description of them would be too technical for these pages.

The paper used for wrapping cigarettes has frequently been the subject of most unwarranted attacks and the most absurd statements have been made regarding it. Investigation and analysis of the paper used in the very cheapest grades of cigarettes by competent authorities have failed to find anything deleterious to health. The paper used for this purpose is made principally in France. It is of the kind known as rice paper although it has no connection whatever with rice. It is a vegetable substance being made usually from the membranes of the bread fruit tree or else from fine trimmings of flax and hemp. The materials are thoroughly washed and treated with lime and soda before and after pulping. Careful analysis are made to see that nothing is left that might be harmful and the manufacturers use the greatest care and judgment to see that their product is as pure and perfect as possible as it is their interest that it should be so. The paper is ex- 
tremely thin and light, very combustible, and gives off very little smoke. These are the only qualities necessary and there is not the least reason to use any harmful ingredients, as the required qualities can be obtained by the ordinary manufacturing processes. Moreover, the best paper can be manufactured and supplied at a very low cost. From France the United States annually imports about $\$ 500,000$ worth of cigarette paper and from Austria about $\$ 120,000$ worth.

Most manufactured cigarettes have a protective tip at the mouth end. This not only keeps the cigarette intact but prevents the tobacca from being wetted by the saliva. As already stated, nicotine is soluble in water, and its entrance to the mouth in this form is thus obviated. The tips are made of various substances, cork, straw, goldleaf, cherry wood, etc., in fact any water-proof substance that is harmless, nonadherent and smooth can be used.

Cigarettes must according to the law of the U. S. be put up in packages of $5,8,10,15,20$, 50 or 100 , and the packages must not contain any lottery or chance ticket nor any indecent picture.

Much criticism, that is to a large extent groundless, has been directed against the habit of cigarette smoking. It has been shown by 
many investigators that when not carried to excess the cigarette is the safest method of using tobacco. The reader is referred to the remarks regarding cigarettes in the chapter respecting the effect of tobacco on the human system; but it may be as well here to quote a recent editorial from one of the leading representative medical journals of the United States, the opinion stated in which should go far towards removing the absurd prejudice against the cigarette.

From the Nere York Medical Journal of July 25, 1914 (Editorial):

"Particularly do the uninformed enjoy an attack on the cigarette; it is cheap; it is small; and its patrons, numerous as they are, yet form an insignificant minority in our immense population. Therefore, the cigarette and its users are fair game for cheap and silly sneers; sneers which are capable, however, of cowing an entire legislature, as in Georgia at this moment. Yet, beyond cavil, it has been proved scientifically that of all methods of using tobacco, cigarette smoking is the least harmful. Some months ago the Laucet undertook a careful laboratory study of the various ways of consuming tobacco, with the result that it was found that the cigarettes, Egyptian, Turkish and American, yielded the least amount of nicotine to the smoke 
"formed; the cigar came next in point of harmlessness, while the pipe overshadowed the cigar to the extent that from 70 to $90 \%$ of nicotine was said to exist in its smoke.

"As to the paper of cigarettes the attacks are simply preposterous.

* * * * * * *

"Men are well within their rights in forbidding cigarette smoking and other pleasures and distractions to their employes; it is another matter when they seize an opportunity to compound with vices they have a mind to, by damning one they're not inclined to, especially when the latter affords solace and recreation to millions perfectly capable of judging what is and what is not good for them. In Europe where a good deal of logical thinking still prevails, there is probably not one smoker of distinction in any walk of life who does not include the cigarette in his nicotian armamentarium."

(See references end of Chapter XV) 


\section{CHAPTER XV}

\section{SNUFF}

How made. Qualities. Description of KINDS. 



\section{SNUFF}

A century ago snuff taking was the principal form in which tobacco was used. The custom pervaded all classes of society and it was used by both sexes. The habit has to a very large extent died out; and it is rarely now that one sees a snuff box in use. Nevertheless there is still a very large trade in snuff manufacture, and it is used very extensively in many countries. It will surprise many to know that about 24 million lbs. of snuff are manufactured and used annually in the U. S. and that within recent years the percentage of increase in the use of this form of tobacco has been higher than in the case of cigar, cigarette or pipe smoking kinds. The value of the snuff manufactured annually is appraised for revenue purposes at about 6 million dollars.

The process of the manufacture of snuff or tobacco powder, is essentially based on long and thorough fermentation as all bitter substances, acid and essential oils, as well as a large part of the nicotine, must be removed.

Strong, coarse tobacco is suitable for the purpose, the darker types of Virginian and Tennessee tobaccos being used. Strong tobacco does not necessarily contain a high percentage of nicotine as is usually supposed. Strength 
has nothing to do with nicotine content; but whatever amount of nicotine the tobacco possesses, at least one-half must be removed by fermentation. As a general rule tobacco leaf which is at least 2 years old is used and this is submitted to a further fermentation process of a special kind for a period varying from 2 to 6 months. When the fermentation process is complete, the tobacco, while still in leaf and unpowdered, is technically known as snuff: There are two principal kinds of snuff and there are many varieties of each kind principally differing in flavor and minor qualities.

The two kinds of snuff are known as Wet and Dry. These terms are due to the difference in the mode of manufacture.

In making wet snuff, the tobacco leaves are ground up into grain form before the fermentation takes place. It only becomes snuff when the fermentation is completed.

In the dry kind the grinding does not take place until after the fermentation is completed, when the fermented leaves are thoroughly dried.

The grinding is then done in a muller similar to a mortar and pestle-this operation being conducted by machinery on a large scale. After grinding the snuff is put through a sieving process and is then sent to the seasoning depart- 
ment, thus occupying from 2 to 6 months or even longer.

Various flavors-attar of roses and such like-are added to give the snuff different scents and flavors.

The various names under which brands of snuff are put up are survivals of names applied to snuff made by methods no longer in vogue: Scotch Snurfs are all dry. There are various kinds - strong, plain, sweet, salt, hightoast, etc.

MассавоY is a semi-wet snuff.

Swedish Snuffs usually contain a large percentage of moisture. The grains are coarse and usually highly. flavored. Snuff taking is still extensive among the Swedish people.

RAPPEE is a snuff made after the French fashion.

\section{REFERENCES (Chapters IX to XV)}

U. S. Dept. of Commerce. Bureau of the Census. Report of 13th Census, 1910. (Vol. on Manufacturers, 1912-1913.)

U. S. Dep'r. of Commerce and Labor. Burtau of Corporations, Report of, the Commissioner of Corporations on the Tobacco Industry. Vol. I, 1909, Continued. 
IvENs, W. M. Brief and argument in certain appeals from the Circuit Court of U.S. for Southern District of New York. (Tobacco Monopoly, 1911.)

Hoagiand, I. G. The Tobacco Industry. In Quarterly of the National Fire Protection Assn., 1907. Vol. I, Nos. 2 and 4.

Jaconstern, M. The Tobacco Industry in the U. S. New York, 1907. 


\section{CHAPTER XVI}

\section{SMOKING PIPES}

History. Materials used in making. Meerschaum. Briar noot. Amber. Special KINDS OF PIPES. CARE OF PIPES. 



\section{PIPES}

The history of tobacco smoking pipes began with the discovery of tobacco by the Spaniards. How long before that event they were used is not known, but that they were used by the Indians and others for a long period is quite clear from many items of evidence. The reader who desires information concerning pre-Columbian tobacco pipes is referred to the Pipes and smoking customs of the American Aborigines, by J. D. McQuire, based on the material in the U. S. National Museum 1889, and other similar archaological works.

The first mention of pipes in literature appears to have been made by Oviedo in 1535 in his work La historia general de las Indias (Part 1). In this there is a small wood cut which is the oldest known picture of a pipe. This pipe was shaped like a Y-the two ends of which were placed in the nose and the tobacco leaves in the stem. The smoke was inhaled. Oviedo says that this pipe was called "Tabaca" from which the name tobacco was probably derived. Admiral John Hawkins was the first to mention the pipe in English literature in 1564.

Raleigh's famous smoking feat did not take place until 1586. 
The Indian pipes were principally of clay and this material was used in England for the first pipes made there and continued in sole use for about 250 years. From England it came to New England, with the first colonists. The Spaniards of South America did not generally use pipes. Meerschaum as a pipe making material was not known in Europe till 1723. It came about in this way: There was then in Pesth (Austria-Hungary) an honest old shoemaker, Karl Kowates, who, when he was not making or mending shoeś, made pipes. Count Andrassy, was one of his pipe patrons. The Count while on a mission to Turkey in $\mathbf{1 7 2 3}$ was presented with a lump of meerschaum. The lightness and porosity of the material suggested to him that it would be a very suitable substance for a pipe bowl and on his return to Pesth he handed the lump to Karl to make a pipe of it. It seems Karl made two, one for the Count and one for himself. But Karl did more than that. The nature of his shoe work made his hands waxy and he noticed that wherever the pipe was waxed by his hands it turned into spots of clear brown color. He thus discovered the coloring qualities of meerschaum. Karl's first pipe is still preserved (it is said) at Pesth.

The new material became very popular and it spread from Austria all over pipe-smoking Europe. 
Wooden pipes do not appear to have come into use till the early part of the 19th Century.

There is a good deal of interesting lore concerning early clay pipes into which it is not proposed to enter here. It will be interesting, however, to note that in William Penn's land transactions with the Indians, 300 clay pipes (probably English make) were one of the articles of barter.

The earliest clay pipe stems were about 9 inches long. The long stem pipes with glazed ends were introduced about the year 1700 and were known as "Aldermen." The pipe known as the "Churchwarden" with a very long, thin, curved stem which was typical of a leisurable smoke did not come into use till about 1819 . In those days smokers did not commonly carry pipes around with them. When a man arrived at an inn or tavern he ordered a pipe and tobacco, just as he ordered his dinner. The "Cutty" or "Aberdeen" with the short stem was, however, used by those who needed a pocket pipe.

It is very surprising how little changes the pipe has undergone. The original pipe was a simple bowl and stem, and the best pipe today is a plain bowl and stem; for although hundreds of devices and all kinds of patents have been tried, the true smoker prefers the simple 
plain pipe which offers no obstacle to the clear drawing of the smoke from the burning tobacco. The materials used for pipes differ in various countries. Pipes are made of clay, porcelain, wood, metal, glass, ivory, horn, cane, bamboo, stone, etc. There is no know material which in the opinion of smokers equals genuine meerschaum as a material for pipes. This is on account of its lightness, its coolness, its absorbing qualities and its capabilities of high polish and assumption of a beautiful color when used from soaking the essential oils of the tobacco. Its friability, however, renders it more suitable for use as a home pipe than for a work-a-day pipe.

For the work-a-day and knock-about pipe the wooden pipe with short stem is without a rival. The qualities which are essential for a wooden pipe are many and it is difficult if not impossible to get any material that will answer all of them. The wood for such a pipe must be hard and practically incombustible, yet light. It must be sapless and inodorous so that when heated the fragrance of the tobacco would not be mingled with that of the wood and be lost. In addition it must be a good absorber, cool and have beauty of grain and be susceptible of a high polish and must not be brittle. The wood known as briar root possesses these quali- 
ties to a greater extent than any other wood known. It will be described in more detail later.

Myall, a native Austrian wood of a very dark color, hard and of good grain has many excellent qualities for pipes, but is brittle.

Maple, junipe and cherry. and several other woods are used to a limited extent.

\section{Meerschaum}

Meerschaum is a light, porous, clayey substance composed of magnesium, oxygen and silicon. It is chemically described as a hydrated silicate of magnesia and its chemical formula is $\mathrm{Mg} \mathrm{Si}_{2} 04+2 \mathrm{H}_{2} \mathrm{O}$.

The work meerschaum is composed of two German words, i. e., Meer, the sea; and Schaum, foam, and literally means "the foam of the sea." A popular belief being that the substance was petrified sea foam.

The circumstances under which meerschaum came to be used for smoking pipes have already been detailed. Meerschaum occurs as a mineral more or less scattered all over the world, but the largest quantities and probably the best qualities occur in Asia Minor. In the United States, the mineral is found in South Carolina. Other mines occur in Spain, Greece and Morocco. The principal mines in Asia Minor are situated about 250 miles southwest of Constan- 
tinople, on the plains of Eskishahr. Meerschaum has been in use for sundry purposes in the Orient for many centuries and the mines of Asia Minor have been worked for at least 1,000 years. The result is that they are now approaching exhaustion. The area in which the mineral occurs principally is small, about six square miles, and in this area many thousands of pits are worked. The soil is alluvial and in these deposits the meerschaum is found in soft lumps and nodules having no definite or regular shape. It also occurs in veins among the Serpentine rocks and marls. Although it is soft when taken out of the ground it rapidly hardens when exposed to the air. It is roughly shaped and cleaned at the mines and from thence sent to the dealers who further prepare it by waxing and polishing and put it on the market in the conditions in which it reaches the pipe makers. The principal European depots for meerschaum are Constantinople and Vienna. It is usually packed in boxes containing about 50 lbs. each and sells for from 50c to $\$ 4.00$ per lb.

The lumps on reaching the manufacturers are first cut with a band saw into suitable sized blocks according to the size and shape of the pipes desired. These blocks are then thoroughly soaked in water until they are thoroughly saturated. The soaking renders the material 
soft and soapy and gives it the consistency of cheese, so that it is then easily shaped into the desired form which the pipe is to take. It is then dried and hardened again and on completion the bowl is hollowed out and the stem drilled. If the pipe is a plain one without carving it is finished on a lathe and filed ready for polishing. It is also threaded for the mouthpiece. The pipe is then sent to the drying room for such time as is necessary to expel all moisture. The final treatment for the smoothing of the surface is done by fine sandpaper and other special substances, then immersing in melted white beeswax for three to five minutes and finally the giving of a high polish with precipitated chalk, cotton and flannel being the usual rubbing materials used.

Meerschaum by its nature is particularly adapted for carving. The hand carving of such pipes requires artistic and dexterous craftsmen, who are experts in this particular class of work.

There are various imitations of meerschaum. One is made from burnt gypsum soaked with lime in a solution of gum arabic. This forms a hard, creamy plaster and is capable of receiving a highly smooth and polished marble-like surface.

Another form of imitation is made of a hardened plaster of Paris highly polished and tinted 
in a solution of gamboge and dragon's blood, being afterwards treated with paraffin or stearie acid. All cheaper grades of meerschaum pipes, holders, etc., are made of this or similar compounds and it is very hard for the average smoker to distinguish them as the ordinary tests will not suffice. The absorption and coloring qualities are about the same. Such imitations cost about half as much as the genuine article or even sometimes less.

It should be added that the chips and dust resulting from the working of the genuine meerschaum are bonded together with a solution and moulded and this is also sold as meerschaum.

The number of genuine meerschaum pipes annually manufactured is probably much less than one-half a million, while there are probably three or four times as many imitations.

\section{Briar Root}

As we have seen briar root is found to be the most suitable wood for pipe smoking. The word briar is not named from wild briar. The word is a corruption of the French name La Bruyère, meaning the heather shrub of that name which grows along the Mediterranean coast of France, Spain and neighboring countries. It is the root of this shrub which is the substance used. The shrub is especially cul- 
tured for the purpose of pipe making; but the area in which the best briar root grows is very limited. It takes considerable time and the result is that the supply of the most suitable wood is far below the demand. The cultivation of the briar root is a simple matter. It consists merely in pruning the growth as much as possible so as to encourage and strengthen the roots.

The very best qualities of briar root come from Corsica and the neighborhood of Leghorn. It is very finely grained, hard and tough, does not char and heats slowly.

When full grown and ready for the market the wood is rough sawn into blocks, varying in size from 3 inches square up, according to the market sizes required, and allowed to season. When fully seasoned the blocks are packed in boxes each containing from 200 to 300 of these blocks. They are then sent to the dealers or direct to the pipe factories as the case may be.

In the factory the blocks are sorted and then undergo a sweating process in steam vats for ten to twelve hours. This steaming gives the wood the familiar brown-yellow tint of the natural briar root uncolored. After sweating the blocks are sent to the drying room as all traces of moisture must be removed. This usually takes several months. For pipe making the workman selects his block and roughly trims 
it to size. It is then placed in the frazing machine. This usually has three cutters revolving at very high speed, making several thousand revolutions per minute. The center cutter shapes out the block and the outer knives cut away the wood on the outside so as to form the block roughly into the shape of a pipe bowl and stem. This is then placed in a special lathe for cutting irregular forms. It is usual to fit in it a metal pattern of the particular shape chosen for the pipe. A circular cutting tool is set in motion and the briar block, which turns with the metal pattern, is mechanically cut to the exact shape of the pattern. After cutting, the pipe passes to the sandpapering machines where both inside and outside are thoroughly treated. and it gets a first polishing or smoothing on a pumice stone wheel. The next process is the boring of the stem which is done in a drilling machine by a steel wire having a cutting top rapidly turned by a lathe. The thread on the end of the stem for the mouthpiece is formed by a special machine. The pipe is then ready for polishers and finishers. It is first sandpapered four times, twice with rough and twice with fine on revolving wheels. Unless the wood is to be left its natural color, it is dropped into a vat of stain until it acquires the color desired. After drying it is ready for "buffing." A "buff" 
is a wheel made of many layers of cloth, leather, etc., which revolves very rapidly. For pipe buffing these buffs are usually Tripoli buff, sheepskin buff, muslin and cotton flannel buff. The Tripoli takes off any sediment held by the edges of the grain. The sheepskin buff burns the color fast into the wood. The muslin and cotton bring out the grain and gives the wood its final delicate lustre and finish, which are done when the stem and mountings have been put on. The pipes are then ready for final stamping with name and packing. The process is much the same with all other hard woods. Pipe factories are found in most countries. French briar pipes are justly celebrated, but the American pipes are better made.

Within recent years calabash has come into vogue to a large extent as a pipe making material. The calabash is a South African squash and has a special softness of flavor. The curved stem end of the calabash is used, being lined with plaster of Paris, and quite a large trade has sprung up in South Africa in growing calabash for the pipe trade, the principal point being Cape Town.

\section{The Pipe Stem}

It is very important that suitable material be selected for the mouthpiece of the pipe. In fact 
from many points of view the mouthpiece is the most important part of the pipe for the smoker, because damage to the lips must be particularly avoided, and a defective, rough, or badly madè mouthpiece is apt to cause damage. There are three very important qualities which the material must have: (1) It must be hard enough to resist indentation from the teeth and yet not feel gritty. (2) It must be capable of receiving a perfectly smooth surface and of retaining it under the action of saliva. (3) It must not be a rapid heater so that it will not burn the lips, or crack or splinter under action of heat. Other very desirable qualities are toughness, beauty of appearance and freedom from taste or odor under all circumstances of use.

Amber has a unique place in fulfilling these conditions. Amber is a fossil gum or resin, the juice of pine trees, which in course of time has become petrified like coal.

Amber is found is various parts of the world, but is more plentifully found along the sandy shores of East Prussia bordering on the Baltic Sea. This area was in time long past the site of pine forests. The amber is found very often to occur with lignite or brown coal. It is dug ${ }^{n}$ out of the cliffs or mined like coal out of the ground. Sometimes it is washed in from the 
sea. In size it varies from the size of a pea to lumps as large as an orange. When first dug up it is usually of a pale yellow color, but this becomes darker on exposure. The manufacture of commercial amber is a government monopoly in Prussia. The pieces are all melted down at a temperature of about $550^{\circ} \mathrm{F}$., and then after purification it is cast into slabs about $7 / 8$ inch to $1 \frac{5}{8}$ inches thick and four inches to eight inches long, in which form it is sold to dealers. There are two qualities, opaque and transparent, the opaque being the tougher. The cost varies considerably, the inferior kinds being sold for $\$ 2.00$ per pound, and the finest specimens cost up to $\$ 60.00$ per pound.

By far the largest quantity of amber used for ordinary pipes is imitation amber. The manufacture of this is a trade secret. It is so good and fulfills its purpose so well that only experts can distinguish it from genuine amber. Therc are many substitutes for amber.

Good vulcanite, except for the matter of appearance is little inferior to amber as mouthpiece material. Cut vulcanite is cool and smooth, but moulded vulcanite is liable to be rough to the lips and should be avoided. Vulcanite mouthpieces are usually sold already finished direct to the pipe makers. 
Except for the matter of brittleness unglazed clay is a most excellent pipe stem. Clay is usually cool and very absorbent of the acrid oils occurring in the distillation of tobacco. When the end of a clay stem is protected by a rubber band, it forms a very good mouthpiece. Bone and other materials are also used as mouthpieces. Ebonite is used, but is objectionable because it spoils the flavor of the tobacco. Celluloid is a dangerous substance and should not be used as a pipe stem.

The smoker should avoid biting the mouthpiece as it roughens it. It is far better to discard a mouthpiece when it becomes indented, rough or worn in any way. A damaged mouthpiece should on no account be used when the lips are chapped or lacerated because the irritation may, if continued, lead to ulceration and tobacco juice is not beneficial to skin lesions.

\section{Spectal Pipes}

German pipes are, as might be expected, the most correct in scientific principle. The pipe has two bowls the upper of which is for the tobacco. This fits into a socket which allows the oils and aqueous solutions due to the distillation to pass into the lower bowl, very little getting into the stem. The bowls are usually of porcelain and the long curved stem is of wood mostly cherry. 
The Dutch pipe is similar to the German except that the stem is long and straight which allows the bowl to rest on the ground. The German pipe is usually held in the hand by the lower bowl. In Turkey and Oriental countries the water pipe is used. This form of pipe originated in Persia. The pipe consists of a receptacle for the tobacco, which has a perforated bottom. This holder fits into a cup from which a hollow tube leads into a jar containing water. The tube passes through the stopper of the jar and descends almost to the bottom of the water. Another tube, the inhaling tube, also passes through the stopper of the jar, but does not reach to the surface of the water. On drawing through the inhaler a vacuum is created in the air space above the surface of the water in the jar which induces suction through the other tube below the water level. The smoke therefore bubbles through the water and is cooled before it reaches the mouth of the smoker. It, however, requires a considerable amount of effort to draw the smoke through.

Water pipes are used extensively among the batter classes of the East. Some of them are very gorgeous affairs, the bowls being of the richest crystal and the fittings gold or silver set with gems. Sometimes they have several smoking tubes so as to accommodate more than one 
smoker. The water pipe used by the Shah of Persia is said to be worth $\$ 400,000.00$.

In Turkey the water pipe is known by the name of Hookak. In Egypt it is called Nargeeleh (or Narghile) because the water vessel is usually a cocoa nut for which the Arabic name is Na'rghee'leh. The Hookak usually stands on the floor and is ponderous, with many smoking tubes. The Nargeeleh is a hand pipe.

In Eastern countries, however, besides the water pipe the ordinary clay bowl pipe is used to a very large extent, being fitted with a wooden stem from 3 to 5 feet in length. All these pipes are essentially home pipes, as it is not habitual with the Eastern people to smoke except when seated.

In China both sexes commonly smoke pipesa water pipe made of brass is usually smoked by the richer classes. The poorer classes use a clay pipe with a bamboo stem.

The principal importation into the United States of foreign made pipes and smokers' articles is from Austria, England and Germany. The latest government statistics show that from England \$278,000, from Austria about \$280,000 , and from Germany about $\$ 139,000$ worth of such goods are annually imported. These are principally pipes. Cigarette paper, briar root, etc., are not included in these figures. 
The total importation value in 1912 (exclusive of duty) from Europe was $\$ 1,478,000$.

\section{The Care of Pipes}

An experienced smoker lays down the following rules for the care of pipes. The rules apply whether a man uses one or half a dozen pipes:

(1) When a pipe is used for the first time wipe out the bowl with a cloth. Then thoroughly wet or dampen it. Before the moisture evaporates fill the pipe. Light evenly and be careful not to burn the rim with the lighted match. The tobacco being damp next the wood will not redden there, hence the wood will not char but a sooty film will form.

(2) Ashes should be allowed to remain in the pipe till thoroughly cooled. Then emptied. The object of this is to allow the liquid residue to soak into the pores of the new wood.

(3) Do not scrape the inner surface of the bowl. The thin coating of carbon (the "cake") which is formed on it is a nonconductor of heat and prevents the wood from overheating or cracking. It keeps the pipe cool and is a good absorber.

(4) After half a dozen smokes the rule of removing the ashes should be reversed. They should be removed promptly after smoking. Blow through the mouthpiece after smoking. 
By this time the inner surface of bowl is sufficiently soaked and coated and continuation makes it acrid and sodden.

(5) Always allow your pipe to cool and dry before resmoking. Use pipe cleaners and pipe spoon for cleaning. When the "cake" becomes too thick part of it may be removed but always leave a layer next the wood. Be careful not to scrape the surface of the bowl.

(6) A pipe should not be used continuously for more than a few weeks or a month. It should then be cleaned and allowed rest unused for a while. It is well to allow it to hang where the sunlight can play on it. Acrid matters will dry out and the pipe will be sweet when smoked again. It is a good plan to pack the bottom of the bowl with powdered chalk when it is resting.

When a pipe tastes acrid it requires more than ordinary cleaning. If one has the opportunity a most excellent way is to blow steam through it, first removing the mouthpiece. Another way recommended by a smoker who says it is most efficacious is to fit a cork into the bowl of the pipe. Make a hole in the cork, into which the nozzle of a soda siphon will fit snugly. Direct the mouthpiece into some emptying vessel and force about a wine glass of the soda 
water from the siphon through the pipe. It will clean it out effectively.

If you are smoking a meerschaum and desire it to color well and evenly it is a good plan to use a false upper bowl to fit inside the bowl of your pipe. The rim of fire where the tobacco is burning makes the pipe bowl too hot and does not allow that part to color. The false bowl will prevent this. Some smokers think that covering a meerschaum bowl with chamois will cause it to color well. The chamois will not aid the coloring but it will protect the bowl from being touched by the hand during the process and thus avoiding a spotty effect, particularly if the hand should be moist or greasy. During the progress of the coloring the pipe should never be allowed to get too hot. The time required to color a pipe depends on the tobacco used. If it is a rich oily tobacco, the time necessary is shorter than with a dry tobacco.

Imitation meerschaum of the cheaper kind are sometimes artificially colored by the makers. This is done by boiling the pipe in an oily solution of nicotine, the formula for which as given in the American Druggist, V. 58, is :

Crude nicotine (oil of tobacco) $=\mathrm{z}$.

Olive oil $=$ 节 ii.

Yellow wax $=$ 亏 viii. 
The pipe is kept in the boiling solution from 10 to 15 minutes and rapidly absorbs it. The surface is capable of a high polish.

\section{REFERENCES}

Penn, W. A. The Soverane Herbe: a History of Tobacco. London and New York, 1901.

Fairholt, F. W. Tobacco; its History and Associations. London, 1876. 


\section{CHAPTER XVII}

\section{EFFECTS OF TOBACCO SMOKING ON THE HUMAN SYSTEM}

Physical effects. Opinions of medicat men QUOTED AND DISCUSSED 



\section{EFFECTS OF TOBACCO SMOKING ON THE HUMAN SYSTEM}

It is a matter of very great importance for the user of tobacco that he should have clear information regarding the beneficial and harmful effects of tobacco on the human mind and body. There are very few matters which have been the subject of such varied opinions; such exaggeration and misconception. Those who are opposed to the use of tobacco have not hesitated to ascribe to it every form of evil, physical, mental and moral. Insanity, epilepsy, cancer, malignant throat disease, blindness, heart disease and a host of bther diseased conditions are traced to tobacco smoking by its enemies. On the other hand the users of tobacco are scarcely less vehement in holding that no harmful effects follow, but ascribing all kinds of virtue as resulting from its use. It is not our object in this chapter to justify or recommend the use, or to advise the avoidance of tobacco; we think it is a matter that the individual should decide for himself. Moreover, we think that no general rules governing all cases can be laid down, but that each individual must judge for himself whether the use of tobacco is justified in his own particular case or not, taking into consideration all the circum- 
stances that affect him. The important thing is that he should possess clear and correct information with regard to the effects of tobacco as far as such have been scientifically determined; and from the observation of its effects on his own organism to determine whether in his own case the practice is beneficial or otherwise and to what extent it may be pursued if he desires to smoke.

We, therefore, purpose to submit the facts which have been determined by the most careful scientific investigators and others of high standing, who, from their experience in the investigation of the causes of disease, are best qualified to offer opinions which may be accepted us authoritative.

A perusal of the vast amount of literature both for and against the use of tobacco brings out certain points very largely. First, in the case of the opponents, the most sweeping statements are made without a particle of scientific proof in support of them, by persons who are in no way qualified to make such statements. Statistics are quoted most recklessly and accepted as conclusive, although in most cases there is no logical connection between the matter of the statistics and the absolute effects of tobacco. If there is a question of a certain condition, it is not sufficient to show that the 
person suffering from it was a user of tobacco and to allege, therefore, that tobacco was the cause of the condition. It must be shown conclusively that no other circumstances than the use of tobacco could have caused this condition. Dr. T. W. Jenkins, of Albany, N. Y., (New York Medical Journal, 1915, V. 102, p. 355), who was awarded a prize by this leading medical journal for his essay on tobacco smoking says: "The first thing to bear in mind is that considering the large amount of tobacco used very little harm results, and care should be taken not to incriminate tobacco when the troubles under observation may be due to other causes."

Secondly, among the investigators themselves who have made impartial inquiries about the effects of tobacco, there is sometimes a wide difference of opinion in the interpretation of results and in the relation of cause and effect. Thus most varied opinions exist on the subject of nicotine. The result is that it is difficult for the average man to come to a satisfactory conclusion on the subject; for it cannot be said that the scientific knowledge of the effects of tobacco smoking on the human system as presented to us today is final or sufficiently well determined to enable definite and true conclusions to be arrived at. 
Thirdly, there is the widespread error of ascribing the evils of the abuses of tobacco to the use of tobacco. This matter of the use and abuse of tobacco cannot be put too clearly. Most medical investigators have based their results clearly on the excessive use of tobacco. It is a very rare thing to find a medical investigator drawing attention to any harmful results following the moderate use of tobacco, and it appears a just statement to make that the majority of men use tobacco in moderation. It appears to be true that excessive smoking is harmful and is capable of producing deleterious effects on the respiratory and nervous systems in man, but it has never been scientifically proved that the moderate use of tobacco has any particularly harmful effects. Moreover, it is well-known to the medical profession and so stated constantly that in many cases where the use of tobacco has produced bad effects on the eye, nerves, etc., its use is contra-indicated, owing to the condition of the subject due to other causes and that such results would not occur in a normally healthy subject. Therefore, because tobacco when used excessively or when used by persons who are not constitutionally fitted for it, produces bad effects, it is not logical to argue, as many opponents of tobacco 
smoking do, that the use of tobacco is universally harmful.

Fourthly, the conclusions arrived at by some investigators, are based on experiments made on animals, and it appears quite open to criticism, and is in fact disproved by common experience, that such results will follow when applied to man. Hinging on this is the question of immunity and toleration. The human system will easily after use tolerate effects which at first it rebels against. This may easily be seen in muscular and other efforts. Let a man who is constantly leading a sedentary life suddenly walk 10 miles. The result is almost prostration and he will not recover from it for a considerable time. Let him, however, commence by walking a mile or two and gradually at each walk increase the distance, and in a short while he will be able to walk 10 miles without feeling any fatigue. Similarly running or other rapid exercise to a person not used to it will produce such rapid disturbances in the respiration and circulation as even to be fatal, while the seasoned athlete may perform such feats without the least ill effects.

To take animals or persons who have never before used tobacco and to argue or conclude that the effects of tobacco smoke on them are the effects of tobacco on smokers generally is 
absurd. Yet such experimental results are very often made the basis of denunciation of tobacco smoking.

Finally most investigators have made their inquiries for the exclusive purpose of discovering the evil effects of tobacco smoking. They proceed to their work with a biassed mind. They have already assumed that the habit is harmful and they simply want to find out how much harm they can discover. They are prejudiced from the beginning. It is to this class of investigator that Dr. John Aikman refers to (New York Medical Journal, Oct. 30, 1915), when he says: "In reading the literature on the use of tobacco we are impressed by the fact that much of it is written by persons greatly opposed to the use of the plant, and naturally prejudiced." It is quite conceivable that a man may investigate the evil effects which follow from wearing clothes and shoes and he could undoubtedly find some evil effects; but the users of such articles could very justly say that the beneficial results of such habits more than outweighed the demonstrated harm that might occur. And then the user of tobacco might say that the beneficial effects of smoking more than compensated for any slight harm that may happen. For tobacco has undoubtedly many excellent effects, and no one knows this better than 
the smoker himself. He will readily admit that excess is bad. He will readily admit that the use of tobacco is not suitable to immature persons, or in fact to many other persons, but he insist that in the majority of cases, it is not only practically harmless but that it has many desirable qualities, for that is proved by his own experience and the experience of millions of other smokers in all ages and under all conditions:

We will now proceed to consider some of the effects which. have been ascribed to tobacco smoking and give expressed opinions concerning them.

Physical Efrects of Tobacco Smoking

The principal deleterious effects on the human system ascribed to the use of tobacco are:

(a) Throat diseases.

(b) Disturbance of vision.

(c) Heart troubles (smokers' heart).

(d) Disturbance of the digestive organs (dyspepsia, etc.).

(e) Disturbance of the nervous system.

(f) Disturbance of nutrition.

As regards (a) throat diseases, the following is the opinion of Dr. H. Reik of the Johns Hopkins University, surgeon to the Baltimore Eye, Ear and Throat Hospital, as expressed by him 
in the Boston Medical and Surgical Journal, Vol. 162, p. 856, 1910 :

"There is not one scintilla of evidence that malignant disease of the throat is due in any way to the use of tobacco; and if it be admitted that carcinoma (cancer) of the lip or tongue has been produced by smoking, it is clearly not tobacco, but traumatism (i. e., injury) from the stems of the pipe or other tobacco container that is responsible.

"It does not appear or at least has not been proven that tobacco causes any definite characteristic lesions of the nose, throat or ear."

Dr. Reik is a man of high standing in the medical profession. His opinion is clear and unmistakable and it is presumed he has seen thousands of cases of nose and throat diseases and knows what he is talking about.

Dr. Reik refers to the question of so-called smokers' cancer. Cancer is a disease which attacks all kinds of people and may occur in widely different parts of the body. The causation of this disease is not known to the medical profession but what is known about it is that it usually occurs on the site of some previous injury. Thus cancer may occur on the tongue as the result of the constant irritation of a jagged broken tooth. 
Dr. I. C. Bloodgood (Boston Medical and Surgical Journal, No. 2, 1914), who has examined 200 cases of lip cancer says that smoking is a common factor, the disease when occuring being usually on the site of a neglected and ulcerated smoker's burn. The burn may be a charring of the skin due to a very hot pipe stem or burning cigar stem. He says, moreover, that if the burn is not continued and there is no other injury, this defect may heal without evidence of ulceration.

Similarly a cancer may be the result of continual use of a broken or rough pipe stem or from using a pirty pipe stem on a broken skin. All these are clearly matters which the average smoker easily and usually avoids. It is, however, clear that tobacco itself is in no way responsible' for cancer, and no responsible medical writer on the subject alleges that it is.

Most of the medical writers who have inscribed injurious physical effects on the nervous system, heart and sense organs, to excessive tobacco smoking have stated that these effects are due to the toxic action of the alkaloid nicotine known to exist in tobacco. There is a wide difference, however, in the results $o b$ tained by different writers as to the amount of the nicotine in tobacco which finds its way with the tobacco smoke. Moreover, some of the in- 
vestigators who have done very careful work do not consider that nicotine is the toxic element, but the substance called pyridine which is derived from it.

Dr. Bush (quoted below) referring to this matter says:

"From a review of the literature it would appear that extensive studies had been made as to the effects on living organisms of the alkaloid, nicotine. From such studies a great number of writers, especially laymen, have adopted the hasty conclusion that tobacco smoking entailed like results.

"Comparatively few studies have been made of the effects of tobacco smoking on human beings; and such as have been made fail to state if the tobacco used or the smoke produced was examined for nicotine or its congeners. The absence of an examination necessarily causes some doubt in the causative faction of the phenomena. Some authors are rather inclined to conclude that nicotine alone is the pathogenic factor in tobacco smoking, but since the presence of nicotine per se in tobacco smoke is debatable and since other toxic substances are demonstrable, it would seem as if the whole subject still remained open for investigation."

The nicotine contained in ordinary tobacco, according to many authors, ranges from about 
1 to 8 or 9 per cent. Lee's investigation (Journal of Physiology, 1908, p. 335) found that about half of the total nicotine was present in the smoke-according to Lee the pyridin seemed to be entirely without influence.

Lehmann (Archiv für Hygiene, 1909, p. 319) found that from 80 to $90 \%$ of the total nicotine in a cigar or cigarette was to be found in the smoke. He found also that in the case of cigars about 10 to $18 \%$ of the nicotine in the smoke is absorbed by the smoker and that cigarette smoke absorbed by the smoker coutains a less proportion of the nicotine in the tobacco than is the case with cigars. The general opinion is, however, that about one-seventh of the nico$t_{i x} e$ in the tobacco will be found in the smoke.

Entirely at variance with these results are those obtained recently by A. D. Bush, M.D., Instructor of Physiology in the University of Vermont (New York Medical Journal, March 14, 1914), and those obtained in the laboratory investigation by the London Laucet. Bush made long and extensive investigations on the effects of tobacco smoking and criticised the results of previous workers. He shows very clearly that in many cases the conclusions drawn by them as regards nicotine contained in tobacco smoke are either entirely erroneous or that the deductions made from the investiga- 
tions were not warranted by the facts observed. He points out the fact that most writers on the subject have overlooked the fact of the great discrepancy between the possible effects arising from the administration of the amount of nicotine in a cigar and the actual effect produced on the smoker of the cigar. He asks this pertinent question: "If a cigar contains 0.085 grains nicotine, and if one-seventh of the nicotine of the tobacco is present in the smoke and if but .004 grains is capable of causing death, why does the smoker not absorb enough nicotinc to cause his demise?"

As a result of his careful experiments, Bush found that although nicotine was present in all the samples of tobacco tested there was no nicotine whatever found in the smoke, except in the case of cigarettes and in this case only traces were found. The reason of this is given as due to the rapid burning of the cigarette which did not allow sufficient time for the complete decomposition of the nicotine. Pyridine was, however, found in the smoke of all tobacco burned. Pyridine is only one-twentieth as toxic as nicotine. Bush concluded, therefore, that pyridine and not nicotine is the toxic factor in tobacco smoke. The same fact was stated several years ago by Rideal (Disinfection and. Preservation of Food, London and New York, 
1903, p. 254), who says: "Tobacco smoke, contrary to popular belief, does not contain nicotine, which is decomposed by the heat; but pyridine and its homologues and the beneficial effects of tobacco in many cases of asthma must be attributed to this latter."

The Lancet investigation (see Lancet, Ap. 6, 1912, pp. 944-947) was mode because "a recent review of numerous analysis of tobacco which have been published from time to time raises some doubt as to whether the results given correctly represent the actual alkaloidal contents of the tobacco." Moreover, to find the relationship of the true amount of nicotine in any tobacco to that in the smoke produced by the combustion of that tobacco, and any modification caused by the method of smoking.

The investigation was conducted under the strictest conditions, the most recent methods of chemical research being employed.

The following table (given by the Lancet) shows the nicotine contents of various tobacco samples and the percentage of nicotine in the smoke : 


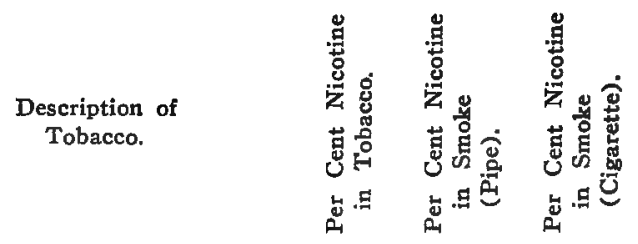

Virginian Cigarettes (Sample 1) .. 1.40

Virginian Cigarettes (Sample 2) $\ldots 1.60$

Caporal (French) Tobacco ....... 2.60

Turkish Cigarettes ............. 1.38

Egyptian Cigarettes ............ 1.74

Pipe Smoking Mixture (1) ...... 2.85

0.74

0.60

0.12

2.20

0.06

....

0.95

....

0.51

2.20

0.21

Pipe Smoking Mixture (2) ...... 2.81

1.53

Pipe Smoking Mixture (3) ..... 2.04

0.23

2.25

Perique Tobacco ............... 5.30

1.27

…

Cavendish Tobacco ............ 4.15

3.85

Latakia Tobacco .............. 2.35

Havana Cigar ................ 0.64

1.20

0.57

From this analysis it appears that pipe mixtures contain the largest amount of nicotine in the tobacco (2.04-2.85\%). Egyptian and Turkish cigarette tobaccos come next (1.381.74\%). Virginian cigarette tobacco shows similar figures (1.40-1.60\%). French tobacco (Caporal) contains 2.60\%, and Perique 5.30\%. For all practical purposes the tobaccos consumed by the public according to this report seldom contain more than $3 \%$ of nicotine and generally less, the average being about $\mathbf{2} \%$, which is much lower than previous writers lead us to expect.

The cigarette, whether Egyptian, Turkish or American, yields the least amount of its total 
nicotine to the smoke formed, while the pipe yields a very large portion (in some cases between 70 and $80 \%$ ) of its nicotine to the smoke. Analysis of cigar smoke gives figures midway between the two.

With the results of Bush and the Lancet before him the user of tobacco will be better able to judge of the opinions of those who describe the effects of nicotine on the vision, heart, digestive organs, etc., as likely to be the results of tobacco smoking.

Thus the disturbance of vision ascribed to tobacco smoking is called tobacco amblyopia.

Dr. W. S. Franklin of San Francisco (Calif. State Jour. of Med., 1909, V. 7, p. 85), says that to produce this disease it is necessary to smoke daily from .75 to $1.0 \mathrm{gms}$. of pure nicotine. If $17 \%$ of the nicotine of tobacco is carried in the smoke, in order to absorb that quantity 7 or 8 cheap domestic cigars, 10 or 11 Cubans or 60 cigarettes should be smoked. Now very few smokers consume this amount and according to Bush, and the Lancet, and others there is no such percentage of nicotine in the smoke.

To the use of tobacco is ascribed an acid dyspepsia-this, however, is noticed more particularly in habitual chewers and in this case the nicotine not being burnt has no chance of 
being decomposed. All writers have agreed that chewing is the worst way that tobacco can be used. Dr. R. V. Dolbey says: (Northreest Medicine, 1909, V. 1 p. 99).

"In chewing, quantities of watery extract of tobacco are swallowed and taken down with the food containing a large percentage of nicotine and causing severe dyspepsia. While tobacco juice solution in the laboratory kills intestinal bacteria, excessive tobacco chewing does not have this effect on the human body owing to the fact that the gastric and pancreatic juices act on it and alter it."

Dr. I. S. Gilfilian discusses the effects of tobacco on the heart in the St. Paul Medical Journal, July, 1912, p. 338. He says that the important part whether organic changes in the cardio-vascular system may be produced by tobacco is still doubtful, and that it has never been shown that smokers suffer more from organic heart disease than nonsmokers.

General opinion is that smoking lessens the pulse rate and slightly increases the blood pressure, and that it is a cause of arterio-sclerosis.

With regard to arterio-sclerosis, Dr. A. Lorand of Carlsbad who is a world-wide authority on the effects of toxic substances on the blood, says in his book, Old Age Deferred (English translation, 1910, p. 367): 
"Clinically we have observed the great frequency of arterio-sclerosis in great smokers, but we do not think that two or three light cigars a day, but never before meals, can do any harm save in exceptional cases. Indeed there are a few instances of persons living to be over 100, notwithstanding the fact that they were smokers-a fact contrary to the observation of Hufeland who pretends that he never heard of such a case. The famous English painter, Frith, who died in October, 1909, used to smoke 6 cigars a day, and Mr. F. of Chartres, in France, passed last year his 100th birthday in spite of his having taken snuff all his life."

If there were any serious lesions caused in the human system by the continued use of tobacco we might naturally expect that life insurance, companies would take notice of it, but hear what they have to say (Medical Record, New York, July 12, 1913) :

Dr. H. G. Turney, at the meeting of Life Insurance Medical Officers Association, London, January, 1913, said that as far as observation and study of the literature went he did not consider that there was much evidence that the habit of smoking can be convicted of any serious effect on the mortality table. One must confess rather to a feeling of surprise that the life-long absorption of so potent a drug as 
nicotine by a large proportion of the male population should not be accompanied by more obvious results in the way of serious injury to the cardiac muscle than appears to be the case.

Dr. A. Marvin of the Department of Pharmacology, Vermont University, made numerous experiments on the effects produced by tobacco. In the cases of the respiratory system, he states that in rapid smoking the respiratory rate is increased, due more to the effort than to the drug. In deliberate smoking there is very little effect. In the digestive system the effects produced were, increased flow of saliva and stimulation of the mucous membrane of the stomach and intestines. Marvin did not find any important symptoms of systemic irregularities except where there was excessive use of tobacco. He says: "Tobacco produces, when used to excess, symptoms in a very small per cent and often it is only one factor in producing the conditions observed." A very cautiously expressed and noncommittal opinion.

It is to be remembered that of the percentage of nicotine in tobacco smoke only a small portion is drawn into the smoker's system. The greater part passes off again in the smoke passed out; also that the products of combustion of tobacco include acqueous solution as 
well as smoke; it will not probably be questioned that some of this watery solution is drawn into the mouth as well as the smoke and probably contains minute quantities of nicotine or its derivatives.

The smoker may obviate any slight harmful effects of these substances by care. If he is a cigar smoker he must avoid chewing or sucking the butt end of the cigar in which the acqueous solution finally gathers, and he would find it better to smoke long thin cigars which afford a small area behind the burning point for the collection of acqueous vapor and give a better combustion. Judged from these viewpoints the best and most expensive thick cigar is likely to be more harmful than the very worst kind of a cigarette, for although there may be a much smaller percentage of nicotine in the cigar tobacco, a much larger proportion of it may reach the mouth of the smoker through the water produced by combustion, in the case of the cigar than in the case of the cigarette.

Every cigar and cigarette smoker should use a holder for the reason stated. The cigarette from the nicotine point of view is the least objectionable form of smoking. In fact expert opinion is recognizing that unless where the smoke is inhaled cigarette smoking if not excessive is probably harmless. It is hard, of 
course, to kill a popular prejudice, but we have to deal with demonstrated facts not prejudices. In the case of inhalation of cigarette smoke the danger is from carbon monoxide gas and not from nicotine.

When the difference of opinion amongst authoritative investigators are discounted their general results will be found to agree very well with the general facts observed by all users of tobacco. What they see is that probably seventy per cent of the adult male population under all conditions and circumstances use tobacco within limits of moderation. They see around them men who have for many years used it, and they do not observe any particular harmful results in the user of tobacco compared with the nonuser. Men as a rule are not more nervous, more subject to heart troubles or age troubles than women, who as a sex, do not use tobacco. Smokers do not deny and never have denied that the abuse of tobacco is harmful.

The general view that both scientific investigators and popular observation is able to support is well expressed by Clouston, who is a world known authority on nervous and mental disease. (See Hygiene of Mind, 3rd Ed. London, 1906, p. 260.)

"If its use is restricted to full grown men, if only good tobacco is used not of too great 
strength, and if it is not used to excess, then there are no scientific proofs that it has any injurious effects, if there is no idiosyncracy against it. . . . . Speaking generally, it exercises a soothing influence when the nervous system is in any way irritable. It tends to calm and continuous thinking and in many men promotes the digestion of food.

"Tobacco, properly used may, in some cases, undoubtedly be made a mental hygienie."

Mann (Brit. Med. Journal, 1908, V. II, p. 1673), expresses a similar opinion thus: "Most men if they choose to swoke can do so within certain limits without injury to health. Some men can exceed such limits with apparent impunity. The extent of the limitation must be determined by each man for himself." 



\section{CHAPTER XVIII}

\section{THE BENEFICIAL EFFECTS OF TOBACCO}

Its disinfecting action. Protection against infectious disease. Psychological EFFECTS OF SMOKING. 



\section{THE BENEFICIAL QUALITIES OF TOBACCO}

In the previous chapters the possible harmful effects of using tobacco have been dealt with at length. In this chapter we shall deal shortly with some positive beneficial effects.

There is very little doubt that tobacco is a strongly protective agent against infection from disease. Its germicidal qualities are wellknown and recognized. It is now recognized by medical writers that the mouth is one of the principal, if not the principal channel of infection for many infective diseases. The cavities of the teeth are the breeding places of hosts of pathogenic bacteria, of which there are about 100 different varieties arising from decaying food and other sources. These destructive agents, many of them highly pathogenic, easily find their way from the mouth through various channels to the inside of the body. Many infective organisms floating in the air are drawn into the mouth in the act of respiration and this is a common method of falling a victim to contagion.

The effect of tobacco juice on the bacteria of the human mouth was investigated by Dr. W. D. Fullerton and is reported by him in the Cleveland Med. Journal 1912, page 585. 
In his experiments Fullerton used tobacco juice obtained from the human mouth by chewing plug tobacco. $\mathrm{He}$ also used a solution of smoke obtained from a well seasoned pipe. These were first thoroughly sterilized in order to obtain a pure natural mixture of tobacco and saliva. Cultures of well-known species of bacteria were made using every laboratory precaution so as to obtain accurate results. Specimens of these bacterial cultures were then submitted to the action of the tobacco juice. It was found that exposure for one hour killed or rendered innocuous 15 to 98 per cent of the bacteria ; exposure for 24 hours acted similarly on from 84 to $100 \%$. Dr. Fullerton gives his opinion, from his results, that it seems that a pipeful of tobacco was more toxic to bacteria than one chew; but chewing tends to loosen retained food particles, foci of bacteria, etc., and much of this is ejected from the mouth. Fullerton's work agreed very well with the results obtained by other workers in the same line of investigation. In Miller's Micro-organisms of the Human Mouth, p. 246, it is stated that the organisms of the mouth lead only a miserable existence in a mixture of an infusion of tobacco, sugar and saliva; and that the smoke of the last one-third or the first one-fourth of a Colorado Claro cigar sterilized ten cubic centi- 
meters of beef extract solution which had been richly inoculated with bacteria from decayed teeth. Arnold, Lancet (London, 190\%) reports similar experiences with some of the most virulent types of infective bacteria.

Both nicotine and its derivative pyridine as well as the tarry oils resulting from tobacco distillation are strong and effective disinfectants ; and formaldehyde, one of the most powerful germicides known, is so formed. Trillat, Annales de l'Institut Pasteur (Paris), Vol. 19, p. 722, shows that 100 grams of pipe tobacco will yield .063 grams and 100 grams weight of cigar .118 grams of formaldehyde. Also that a dilution of 1/1000 formaldehyde is germicidal to all bacteria although it has very little deleterious effects on man.

As far as can be ascertained there has not been very much investigation for the purpose of demonstrating the actual results of clinical experience regarding the antiseptic qualities of tobacco in the case of smokers, but facts, so far as they have been recorded, bear out the experiments. Rideal Disinfection and Preservation of Food (London and New York, 1903) states that the investigations of Tessarini showed that tobacco smoke passed over the organisms of human cholera and pneumonia killed them in from 10 to 30 minutes. He also states 
that the Cigar Manufacturers Association of Hamburg reported that in the cholera epidemic of 1892 in that city, only 8 out of $5,000 \mathrm{em}^{-}$ ployes in the cigar factories there were attacked by the disease and that there were only 4 deaths. Professor Wenck, of the Imperial Institute of Berlin, has published an account of this cholera epidemic (see Laucett francaise, Paris, 1912, p. 1425). His conclusions favor the preservative action of tobacco. It was clearly shown that slightly moist tobacco was a fatal germicide for the cholera bacillus; all microbes die in it in 24 hours. The examination of cigars made in Hamburg during the epidemic showed that they were absolutely free from bacilli. Wenck asserts also that cholera microbes die in 1/2 hour, 1 hour, and 2 hours after having been placed in contact with the smoke of Brazilian, Sumatran and Havana tobacco. The fumes of tobacco will besides kill in five minutes the cholera microbes obtained from saliva. Fullerton already quoted examined a small number of mouths (74) in the Johns Hopkins Hospital at Baltimore. Of those who did not use tobacco in any form a larger percentage showed signs of dental caries and decay of an advanced stage than in the case of tobacco users. Similarly in the case of women who never used tobacco; and, although there was a 
much greater care and cleansing of the teeth, yet the percentage of decay and disease was higher than in the case of men using tobacco. Fullerton says, "The smoking or chewing of tobacco is decidedly germicidal. Chewing, by exercising the teeth, helps nutrition and eliminates pathological agencies both by destroying them in situ and by removing them in the expectoration." Rideal (already quoted) mentions that Dr. Burney, the senior medical officer of Greenwich Hospital, London, asserts that the tobacco smoking inmates of that institution enjoyed comparative immunity from epidemics.

From these opinions and examples it seems quite clear that whatever portions of the decomposition products of tobacco reach the mouth and mix with the saliva, or propagate themselves in the immediate surroundings of the smoker, are likely to have extremely good effects. It would be easy to multiply these opinions but there is no use laboring the argument. There is a matter, however, it will do no harm to mention here. Today it is being gradually recognized by the medical profession that the conditions which lead ultimately to gastric and intestinal ulcer including appendicitis are entirely due to infection. At the 1912 meeting of the British Medical Association this was clearly manifested and some of the leading 
authorities in England pointed out the importance of the mouth as a focus of infection in such diseases. Now if this is so, it is at once apparent how important tobacco as a mouth disinfectant and germicide becomes; and it may incidentally throw some light (otherwise unexplained) on the fact constantly observed that in persons under 30 years old these diseases are far more common amongst women than in the case of men. The use of tobacco is not asserted as a reason, but it may be.

With regard to other beneficial effectsClouston, Fullerton and Marvin, state that the moderate use of tobacco has a beneficial effect on the digestive system as in general it causes an increased flow of saliva and gastric juice which helps in the digestion of food; it also stimulates the muscles and mucous membrane of the stomach and intestines. The sedative effects of tobacco on the nerves is a preventative of nervous dyspepsia and is valuable for the promotion of good digestion.

While much has been written on the effects of excessive smoking on the nervous system little has been said of the good effects of moderate smoking. Every smoker realizes that the soothing effects of tobacco on the nerves is perhaps its most valuable property. Clouston's opinion, already quoted (and none could be better), is 
that "tobacco exercises a soothing influence when the nervous system is in anyway irritable; it tends to calm and continuous thinking." Fullerton says, "It gives a composure and feeling of well-being which are beneficial to mind and body." Of these facts there can be no doubt because they are matters of common daily observation and experience. Most smokers find a solace and quieting influence from their evening smoke after the worries of a troublesome day which no other agent can give them. The effect produced may be partly psychological but that does not matter. Indeed the strenuousness of life in the age in which we live seems to demand such a help and nothing appears to supply the want so efficiently, so pleasantly, and with less harm, than a quiet smoke. It puts the smoker at peace with himself and at peace with others. Bush found in his investigations on the mental effects of tobacco on college students that there was a temporary loss of ten per cent in mental efficiency in certain faculties of the mind. This is probably true enough though his results are not quite conclusive. On the other hand many men find that they can think more clearly and more consecutively when helped by a smoke. Indeed they smoke when they have a knotty problem to solve. The 
point need not be argued; all smokers will agree with it.

Judged from a psychological standpoint the effects of tobacco are entirely favorable. To the sleepless, the worried, to him who is troubled in mind or vexed in spirit, the pipe or cigar is a never-failing remedy to soothe and cheer. It is the feeling of betterment which it engenders and the spirit of good will which tobacco creates that are responsible for its universal use by men differing widely in grade and condition of life as well as in mental caliber; it reaches the common springs which move humanity; its qualities are those which have made the pipe a symbol of peace and a bond of fellowship and union between man and man from Pole to Pole.

From a general summing up of the opinions which have been quoted the question might finally be asked, "Is tobacco on the whole harmful or beneficial to its users?" The answer seems to be this: "Tobacco to the extent used on the average has some slight injurious effects and some slight beneficial effects on the physical system. It is an excellent preservative agent against contagious and infectious disease. Mentally its effects are overwhelmingly beneficial." In every particular case a man must judge for himself, taking account of his indi- 
vidual idiosyncrasies and conditions whether the use of tobacco is beneficial to him or otherwise.

\section{REFERENCES}

Laucet. London, 1906. Vol. I, p. 984. The germ-destroying properties of tobacco.

AnNold, M. B. On the effects of the Exposure of Tobacco Smoke on the growth of pathogenic micro-organisms. Laucet. London, 1907. Vol. I, p. 1220.

Murray, J. C. Smoking; when injurious, when innocuous, when beneficial. London, 1871.

Lezars, I. The use and abuse of Tobacco. Philadelphia, 1883. 



\section{CHAPTER XIX}

\section{MISCELLANEOUS}

RevenUe, TAXation, ETC., IN CONNECTION WITH tobacco. Free mports. Diseases of ToBacco. Tobacco flavors. Formulat. 



\section{NOTES}

The "per capita" consumption of tobacco in the U. S. has increased from 1.6 lbs. in 1863 to between 5 and 6 lbs. at the present time.

At the present time the United states collects about 70 million dollars annually from domestic taxation on manufactured tobacco; and, in addition, about 25 million in import duties. The actual total income from tobacco in 1912 was 96 million dollars. For the fiscal year ending June 30, 1913, tax was paid on the following "withdrawn for consumption":

Cigars weighing more than 3 lbs. per thousand, $7,699,037,543$.

Cigars weighing less than 3 lbs. per thousand, $1,033,778,160$.

Cigarettes weighing more than 3 lbs. per thousand, 18,194,311.

Cigarettes weighing less than 3 lbs. per thousand, 14,276,771,160.

Snuff, lbs., 33,209,488.

Tobacco, chewing and smoking, lbs., 401,362,620 .

In France, Spain, Austria, Italy and other countries the government has a monopoly over the manufacture and sale of tobacco products. 
Purchase of leaf in the U. S. is made through government agents.

The quantities of tobacco which may be imported "free of duty" into European countries is as follows :

Austro-Hungary-12 cigars, 35 grams tobacco.

Belgium-None.

Bulgaria- 50 cigars, 50 cigarettes, 50 grams tobacco.

Denmark-None.

Egypt-25 cigars, 100 cigarettes, 200 grams tobacco.

France-30 cigars, 300 cigarettes.

Germany-Enough for immediate use.

Great Britain-12 cigars, 20 cigarettes.

Holland-None.

Italy-6 cigars, 15 cigarettes.

Norway-100 cigars.

Portugal-None.

Russia-100 cigars, 100 cigarettes, 100 grams tobacco.

Spain-None.

Sweden-None.

Turkey-None.

In U. S. 50 cigars and 300 cigarettes may be imported free. 
Small variations in the cost of manufacture (including the cost of leaf), which do not exceed $10 \%$, are usually borne by the manufacturer, and do not affect the price to the consumer. But increase in taxation, either internal revenue or tariff, usually occasions a diminution in consumption as it invariably increases the cost.

The diseases of tobacco due to insect PESTS, ETC.

Tobacco, from the seed bed to the storage of the manufactured products, is subject to attack by insects, etc., and vigilance must at all times be exercised to keep it free from such harmful influences.

Only a few of the principal agencies attacking tobacco will be mentioned here as the subject is of more interest to the specialist than to the smoker. The growing plant is particularly subject to Cut-worm disease and Horn-worm disease. Cut-roorms are the larvae of several species of moths. They injure the young, tender plant and feed on the leaves. Horn-worms are the larvae of the Sphinx Moth. 2 or 3 will ruin a plant in one day.

Stored tobacco is subject to many diseases. Bud caperpillars, the leaf-miner or split-reorm 
and the Tobacco flea beetle are minute beetles which attack it. Mosaic disease, Frog-eye or Leaf-spot are probably bacterial diseases.

In addition, tobacco, particularly during the curing process, is subject to pole-burn, polesweat, or house-burn, stem-rot, white-vein, and various forms of mould, all these being probably due to bacteria.

For additional information see:

U. S. Dept. of Agriculture. Farmers' Bulletin, 120.

How ARD, L. O. The principal insects affecting the tobacco plant. Washington, D. C., 1900. U. S. Dept. of Agriculture. Bureau of Entomology. Bulletin 65.

\section{SPECKLed of spotted CIgars}

Many smokers of cigars have the idea that there is some special virtue in a cigar that shows specks or spots of discoloration in the leaf. As a matter of fact such spots have nothing whatever to do with the quality of the tobacco. The occurrence of such spots is accounted for differently. Some say the spots are due to certain bacteria which attack the leaf either when growing or fermenting and this most probably is the correct view. Others say that the spots are due to rain drops which, 
sprinkled on the leaves, act as lenses and concentrate the rays of the sun, thus causing a burning of the leaf in such spots. Some think the spots are caused by a worm. On account of the prejudice of smokers for speckled cigars dealers have been known to produce this appearance in the leaf artificially. There are different methods although resort is not often had at the present time to this practice as the belief in this sign is no longer as prevalent as formerly. The following are examples of such cigar speckling preparation, the chief ingredient being some active oxidizing agent:

Cigar speckling fluid:

(Method 1.) Powdered Ammonium Carbonate and a concentrated solution of $\left(\mathrm{H}_{2} \mathrm{O}_{2}\right)$.

Dissolve one part of the Ammonium Carbonate in 25 parts of the $\left(\mathrm{H}_{2} \mathrm{O}_{2}\right)$. Touch the cigar with this in spots with the end of a pointed stick. This gives the appearance of speckled Sumatran leaf.

(Method 2.) The following method is said to be used by a large firm:

Sodium Carbonate -3 parts.

Chlorinated Lime-1 part.

Mot Water-8 parts.

Dissolve the washing soda in the hot water, add the chlorinated lime, and heat to the boiling 
point. When cool decant and cork tightly. This is sprinkled over the tobacco.-From Amierican Druggest, Vol. 33, p. 328.

Specks are sometimes caused by fluids used to destroy insects which attack the cigar after manufacture.

\section{Tobacco flavoring essences}

In the chapter treating of the manufacture of smoking and chewing tobacco. it was stated that the tobacco leaf was often treated by certain flavoring essences. The following are quoted as examples of such essences:

Cascarilla Bark-1 ounce.

Fluid Extract Valerian-1 ounce.

Tonka Bean-2 drams.

English Rum-3 ounces.

-From Pharmaçeutical Era, V. 21, 1899, p. 252.

The following essences are said to be used in France and Germany:

(1) For every 1,000 kilos. of tobacco take 4 kilos. of purified potash; 5 kilos. table salt; 10 kilos. canella water; 10 kilos. rose water; 5 kilos. melilotte water; 2.8 grams tonka bean; pulverized. Color the whole with 4 grams English red. Add when the tobacco is cut up.

(2) 12 kilos. soda; 4 kilos. salts of tartar; 10 kilos. canella water; 10 kilos. rose water; 5 
kilos. melilotte water; 2.8 grams tonka bean; 4 kilos. simple syrup; 5 kilos. French brandy; 6 kilos. red sandal wood.-From Pharmaceutical Era, V. 24, p. 67.

\section{Cigar Flavors}

Although the best cigars are made from the natural leaf and depend solely on its flavor and aroma, in the inferior article manufacturers sometimes resort to flavoring fluids.

The following examples of cigar flavoring fluid formulae are taken from the Pharmaceutical Era, V. 24, p. 455:

Formula 1.

Extr. Vanilla-1/2 gal.

Alcohol and Jamaica Rum,--each, 1/2 gal.

Tinct. Valerian-8 ounces.

Carraway Seed-2 ounces.

English Valerian Root-2 ounces.

Bitter Orange Peel-2 ounces.

Tonka Bean-4 drams.

Myrrh-16 ounces.

Formula 2 .

Valerianic Acid-3 drams.

Acetic Ether-40 minims.

Butyric Ether--10 minims.

Alcohol-4 pints. 
Formula 3.

Fluid Extr. Valerian-1 ounce.

Tinct. Tonka Bean-8 ounces.

Alcohol-enough to make 16 ounces.

Formula to improve the buRnINg quacities OF TOBACCO

2 lbs. of Saltpeter.

Half gallon of Alcohol ( $100 \%$ proof).

1 gallon Port Wine.

9 gallons Lukewarm Water.

Mix these ingredients thoroughly together, and add to every 100 lbs. weight of tobacco.

OVERCOMING DESIRE FOR TOBACCO

(From The American Druggist, V. 51, 1908.)

Kalometzer (Bulletin Medical, 190\%) states that rinsing mouth with solution of silver nitrate ( $1 / 4$ of $1 \%$ strength) will overcome the desire.

Preventing injurious action of nicotine

A process for the treatment of tobacco leaves preventing in a way injurious action of nicotine and of acrid empyreumatic acid products, was devised some years ago by Professor Gerold of Halle. His process is thus described: He employs for 8 kilograms of tobacco leaves 
containing the usual percentage of nicotine a decoction prepared by boiling 15 grams of tannic acid with $11 / 2$ kilograms of water until the weight is reduced to one kilogram; then 30 grams of the essential oil of origanum vulgare are added, after which the decoction is immediately removed from the fire. Having stond for some minutes the mixture is filtered and allowed to cool to about $16^{\circ} \mathrm{C}$., when the preparation is ready to be spread over the previously weighed tobacco. When the absorption of this mixture by the tobacco leaves is completed, they are subjected to slight pressure and moderate heat, after which they are ready for the manufacture of the various tobacco products.

Tannic acid is a well-known antidote for nicotine poisoning, and it is claimed for Gerold's process that while the undistilled nicotine is neutralized in its toxic qualities only by the tannic acid, that this does not influence at all its peculiar odor nor most of its other characteristics.-From the Pharmaceutical Era, July 27,1899, p. 144 .

Havana cigars are generally better if smoked fresh; domestic cigars are better if allowed to age in the box several months before using. 
Remember that the phosphorus or sulphur of a match may spoil the flavor of a fine cigar. Be careful when you are lighting it to use only the edge of the match flame.

If the total number of cigars smoked annually in the United States were placed end to end they would encircle the whole world more than twenty times. 


\section{INDEX}

Air Curing of Leaf . • • . . . . . . . 66

Amber . . . . . . . . . . . . . . 162

American Production of Tobacco Other Than in

U. S. . - . . . . . . . . . . . 35

Analysis of Tobacco . . . . . . . . . . . 55

Asia, Production of Tobacco in . . . . . . 31

Bacterial Diseases, Effects of Tobacco on . . . 197

Blends of Tobacco, How Made . . . . . . . 78

Briar Root . . . . . . . . . . . . 158

Cancer and Tobacco . . . . . . . . . . 180

Chemical Constituents of Tobacco . . . . . 55

Chewing Tobaccos .. . . . . . . . . . 128

Cigar and Cigarette Holders, Value of . . . . 191

Cigar Business in U. S. . . . . . . . . . 96

Cigar Flavors . . . . . . . . . . . 215

Cigar Leaf Tobacco Grown in U. S. . . . . 119

Cigarette Paper . . . . . . . . . . . . 139

Cigarette Smoking, Criticisms of . . . . . . 140

Cigarettes, American . . . . . . . . . . 138

Cigarettes, Kinds of . . . . . . . . . . 134

Cigarettes, Nicotine in Smoke of . . . . . . 187

Cigarettes, Statistics . . . . . . . . . . 133

Cigarettes, Turkish . . . . . . . . . . 135

Cigarettes, Turkish, Manufactured in the U. S. . 137

Cigars, Classification of . . . . . . . . 104

Cigars, Composition of . . . . . . . . 113

Cigars, Desirable Qualities of . . . . . . . 113

Cigars, Hand-made . . . . . . . . . . 101

Cigars, History . . . . . . . . . . . 95

Cigars, Imported Kinds, in U. S. . . . . . . 114

Cigars, Machine-made . . . . . . . . . 103

Cigars, Manufactured in U. S. . . . . . . 117

Cigars, Speckles or Spots on . . . . . . . 212 
Cigars, Statistics of Production and Consumption in

U. S. . . . . . . . . . . . . . 96

Cigars, Various Terms Regarding . . . . . . 107

Coloring Meerschaum Pipes . . . . . . . 169

Consumption of Tobacco in U. S. . . . . . . . 92

Cuban Cigar Leaf . . . . . . . . . . 118

Cuban Tobacco . . . . . . . . . . . 35

Curing of Tobacco Leaf . . . . . . . . . 63

Digestive System and Use of Tobacco . . . . 202

Diseases of Tobacco Leaf . . . . . . . . 211

Disinfecting Action of Tobacco . . . . . . . 199

East Indian Tobacco . . . . . . . . . . . . . . 38

Europe, Production of Tobacco . . . . . . 32

Exportation of Tobacco from U. S. . . . . . 91

Eyes and Use of Tobacco . . . . . . . . . . . $\quad$. 189

Fermentation of Tobacco, Action of Microbes . . 81

Fermentation of Tobacco, Chemistry . . . . . 80

Fermentation of Tobacco Leaf . . . . . . . 79

Flavoring Essences . . . . . . . . . . 214

Flue Curing of Leaf . . . . . . . . . . . 65

Hand-made Cigars . . . . . . . . . . 101

Havana Cigars . . . . . . . . . . . 115

Holders for Cigars and Cigarettes, Value of . . 191

Infection, Value of Tobacco Smoking Against . . 197

Insects Affecting Tobacco Leaf . . . . . . 211

Life Insurance and Tobacco . . . . . . . 188

Machine-made Cigars . . . . . . . . . 103

Manufactured Products of Tobacco in U. S., Sta-

tistics . . . . . . . . . . . . . . 89

Meerschaum . . . . . . . . . . . . 155

Microbes, Action in Fermentation of Tobaceo . . 81

Mind, Effects of Tobacco Smoking . . . . . 202

Mouthpiece of Pipes, Importance . . . . . . 161

Nerves, Effect of Tobacco Smoking on . . . . 202

Nicotine . . . . . . . . . . . . . . 57 
Nicotine, Amount in Tobacco Smoke . . . . . 183

Nicotine Contents of Tobaccos . . . . . . . 185

Nicotine Effects on Human System . . . . . 182

Open Fire Method of Curing Leaf . . . . . 65

Packing of Tobacco Leaf for Market . . . . . $\quad 69$

Perique Tobacco . . . . . . . . . . $\quad 50,125$

Philippine Cigars . . . . . . . . . . . 117

Pipe Smoking Tobaccos, Kinds of . . . . . . 124

Pipe Smoking Tobacco, Qualities of . . . . . 123

Pipe Stem, Importance . . . . . . . . . 161

Pipes, Briar Root, Making of . . . . . . . 159

Pipes, Care of . . . . . . . . . . . . . . . . . 167

Pipes, History of . . . . . . . . . . . . . . 151

Pipes, Importation of, Into U. S. . . . . . . 166

Pipes, Materials Used in Making . . . . . . 154

Pipes, Meerschaum, Coloring . . . . . . . 169

Pipes, Meerschaum, Making of . . . . . . . 156

Pipes, Special Kinds of . . . . . . . . . 164

Plug Tobacco for Chewing . . . . . . . . 128

Potash, Importance in Tobacco

Psychological Effects of Tobacco Smoking . . . 202

Rehandling of Tobacco Leaf . . . . . . . 77

Revenue Derived from Tobacco . . . . . . 209

Shade Grown Tobacco . . . . . . . . . 25

Smoke, Tobacco, Nicotine in . . . . . . . 187

Snuff, Manufacture, Statistics and Kinds... . 145

Soils, Influence on Quality of Tobacco . . . . 22

Suchsland's Experiments With Bacteria on Tobacco

Leaf . . . . . . . . . . . . . 81

Sumatran Cigar Leaf . . . . . . . . . 118

Teeth and Tobacco . . . . . . . . . . . 201

Terms Used in Cigar Trade . . . . . . . . 107

Throat Diseases Due to Use of Tobacco . . . . 179

Tobacco, Analysis of Contents . . . . . . . $\quad 55$

Tobacco, Botanical Information . . . . . . 15 
Tobacco, Burning Qualities of . . . . . . 216

Tobacco, Culture . . . . . . . . . . . 21

Tobacco, Denicotianized . . . . . . . . . 216

Tobacco, Effects of on Body . . . . . . . . 173

Tobacco, Exportation from U. S. . . . . . . 91

Tobacco, Flavoring Essences . . . . . . . 214

Tobacco, Free Importation in Different Countries . 210

Tobacco, History . . . . . . . . . . . 13

Tobacco Leaf, Prices of . . . . . . . . . . . 71

Tobacco Manufacturing Industry, Capital, etc. . . 89

Tobacco Plant, Varieties . . . . . . . . . 16

Treatment of Leaf Before Manufacture . . . . 82

Turkish Tobacco . . . . . . . . . . . 34

United States, Production of Tobacco . . . . 41

Varieties, Botanical of, Tobacco Plant . . . . 16

Varieties of American Grown Tobacco Leaf . $\quad 44, \quad 46$

Vulcanite, as Pipe Stem Material . . . . . . 163

Warehouse System of Sale of Tobacco Leaf . . 70

Water Pipes . . . . . . . . . . . . 165

Yellowing of Tobacco Leaf . . . . . . . . $\quad 27$ 





